\title{
Bead-based immunocomplex entrapment assays for rapid, sensitive and multiplexed detection of disease biomarkers with minimal user intervention
}

\author{
Yuhui Gong and Gerard Marriott*
}

${ }^{\dagger}$ Department of Bioengineering, ${ }^{\ddagger}$ Tsinghua-Berkeley Shenzhen Institute, University of California-Berkeley, Berkeley, CA 94720, USA 


\section{Supplementary Information Table of Contents}

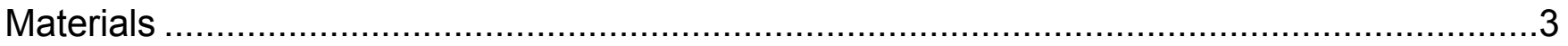

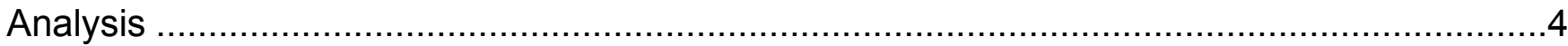

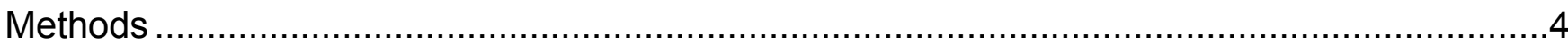

Synthesis of antibody-conjugate and antigen-conjugate .........................................................

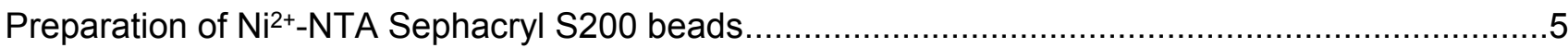

Preparation of thiol-Sepharose 6B beads with immunocomplex ..................................................

Preparation of $\mathrm{Ni}^{2+}$-NTA 6B/Ni ${ }^{2+}-\mathrm{NTA}$ Sephacryl 200 beads with immunocomplex.........................6

Stability test of thiopropyl-Sepharose 6B/Ni ${ }^{2+}-\mathrm{NTA}$ 6B beads containing immunocomplex................7

Kinetic studies of thiopropyl-Sepharose $6 \mathrm{~B}$ beads ...............................................................

The reaction of thiopropyl-Sepharose 6B beads and anti-human IgG-TRITC (capture antibody) ................7

The reaction of TCEP on capture antibody linked thiopropyl-Sepharose $6 \mathrm{~B}$ bead ................................... 8

The reaction of capture antibody coupled thiopropyl-Sepharose 6B bead with human IgG-FITC (target

antigen)

The reaction of TCEP on thiopropyl-Sepharose 6B bead containing capture antibody and antigen complex

Quantitative analysis of fluorescence intensity of beads coupled with different concentrations of antibodies and antigens

Quantitative analysis of mixture of beads containing different concentrations of capture antibodies and antigens

The measurement of thiopropyl-Sepharose $6 \mathrm{~B}$ bead size distribution and beads-immunocomplex

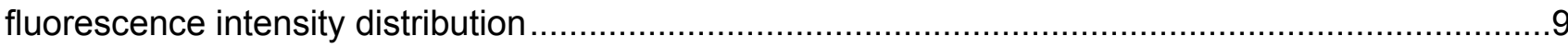

The calculation of amount of antibody and antigen molecules modified on individual bead ..............9

Multiplexed detection of target molecules in single beads...................................................... 10

SDS-PAGE test of thiopropyl-Sepharose 6B bead-immunocomplex consists of anti-HSA IgG and HSA-TMR

Urine tests with thiopropyl-Sepharose 6B bead coupled with capture antibody anti-lgG-TRITC ......11

Urine tests with $\mathrm{Ni}^{2+}$-NTA Sephacryl S200 bead coupled with capture antibody anti-KLC IgG-FITC12

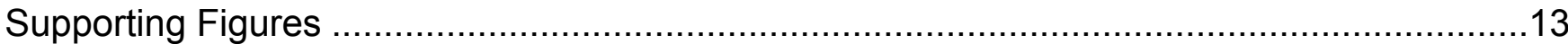

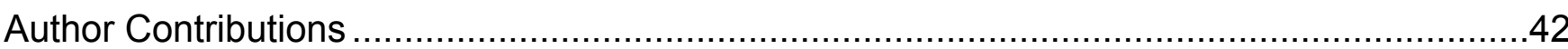




\section{Materials}

Thiopropyl-Sepharose 6B, anti-rabbit IgG $(\mathrm{H}+\mathrm{L})$-Alexa Fluor 532 produced in goat and $\mathrm{PD}-10$ columns (Sephadex G-25 M) were obtained from GE Healthcare Bio-Sciences (various global suppliers). Protino Ni-NTA agarose was obtained from Macherey Nagel GmbH \& Co. KG. Sephacryl 200-HR, ammonium persulfate (APS) ( $\geq 98 \%$ ), sodium dodecyl sulfate (SDS) $(\geq$ 99\%), N,N,N'N'-tetramethylethylenediamine (TEMED) ( $\geq 99 \%$ ), 2-mercaptoethanol ( $\geq 99 \%$ ), Trizma base $(\geq 99.9 \%$ ), tris(2-carboxyethyl)phosphine hydrochloride (TCEP) $(\geq 98 \%)$, DLdithiothreitol (DTT) (molecular biology grade, $\geq 99.5 \%$ ) nitrotetrazolium blue chloride (NBT) (electrophoresis grade, $\geq 97 \%$ ), 5-bromo-4-chloro-3-indolyl phosphate $p$-toluidine salt (BCIP) (molecular biology grade, $\geq 99 \%$ ), 1-ethyl-1-[5-( $N$-succinimidyloxycarbonyl) pentyl]-3,3,3,3tetramethyl-indodicarbocyanine chloride (NIR-641 N-succinimidyl ester) ( $\geq 80 \%), 5$-carboxytetramethylrhodamine $\mathrm{N}$-succinimidyl $\quad$ ester $\quad$ (5-TMR $\quad \mathrm{N}$-succinimidyl $\quad$ ester), $\quad \mathrm{N}$-(2hydroxyethyl)maleimide ( $\geq 97 \%$ ), 1,4-butanediol diglycidyl ether ( $\geq 95 \%)$, sodium borohydride $\left(\mathrm{NaBH}_{4}\right)(\geq 98 \%)$, sodium hydroxide $(\mathrm{NaOH})$ (anhydrous, $\left.\geq 97 \%\right)$, ethanolamine $(\geq 99.5 \%)$, alkyne-poly(ethylene glycol) ${ }_{4}$-maleimide $(\mathrm{Mw} \quad 382.41), \quad$ O,O'-bis[2-( $\mathrm{N}$-succinimidylsuccinylamine)ethyl] poly(ethylene glycol) ( $M w 3000$ ), lgG from human serum (reagent grade, $\geq 95 \%$ ), IgG-FITC from human serum, anti-human IgG (whole molecule)-FITC produced in goat, anti-human-Kappa Light Chain (bound and free)-FITC antibody produced in goat, antihuman IgG (whole molecule)-alkaline phosphatase antibody produced in goat, anti-albumin antibody produced in goat, monoclonal anti-actin-Cy3 antibody produced in mouse, actin from mouse muscle, human serum albumin $(\geq 98 \%)$, bovine serum albumin ( $\geq 96 \%)$, SIGMAFAST Fast Red TR/Naphthol AS-MX tablets, N,N-dimethylformamide (anhydrous, 99.8\%) and dimethyl sulfoxide (GC grade, $\geq 99.5 \%$ ) were obtained from Sigma-Aldrich (various global suppliers). Anti-human IgG (H\&L)-TRITC produced in goat was purchased from Abcam, Inc. (Cambridge, MA USA). Staphylococcal Protein A recombinant-His Tag was purchased at $\geq$ 97\% purity from Prospec-Tany TechnoGene, Ltd. (East Brunswick, NJ USA). Bence Jones Kappa Light Chain protein was obtained at $\geq 95 \%$ purity from Fitzgerald Industries (North Acton, MA USA). $\alpha$-Maleimidyl- $\omega$-amino poly (ethylene glycol) $\left(\mathrm{NH}_{2}\right.$-PEG-Mal) (Mw 10,000) was obtained from Advanced BioChemicals, LLC. (Lawrenceville, GA USA). Maleimide-poly (ethylene glycol)-maleimide (Mal-PEG-Mal) (Mw 3,400), 4 arm-poly (ethylene glycol)maleimide (4 arm-PEG-Mal) (Mw 10,000) were obtained from Laysan Bio, Inc. 1M Tris-HCl pH $8.0 \pm 0.1$ buffer, $1 \mathrm{X}$ phosphate-buffered saline (PBS) were obtained from Corning Lifesciences (Manassas, VA USA). PageRuler prestained protein ladder (10 to $180 \mathrm{kDa}$ ), ELF 97 phosphatase substrate, imidazole and nickel chloride hexahydrate were obtained at $\geq 99 \%$ 
purity from Thermo Fisher Scientific (various global suppliers). Borate buffer (0.05 M, pH 8.5) (ACS grade) was obtained from BioWORLD (Dublin, OH USA). N-(5-amino-1-carboxypentyl) iminodiacetic acid (AB-NTA) ( $\geq 97 \%$ ) was purchased from Dojindo Molecular Technologies, Inc (Kumamoto, Japan). 30\% Acrylamide/bis solution 29:1, Laemmli sample buffer, 10X Tris/Glycine/SDS buffer and Coomassie brilliant blue R-250 staining solution were obtained from Bio-Rad (Hercules, CA USA).

\section{Analysis}

All confocal laser scanning microscopy (CLSM) images were acquired on a Carl Zeiss LSM 700 (Thornwood, NY USA). Raw data was analyzed with Zeiss LSM ZEN 2009 software and Image J program. At least three beads were selected from each sample in above software and the fluorescence intensities of different channels were recorded. The average intensity and standard deviation were calculated. Agilent 8453 UV-visible spectroscopy (Santa Clara, CA USA) was used to record UV absorbance of antibody and antigen conjugates. $500 \mu \mathrm{L}$ of sample solution was transferred into the micro UV-cuvette (BrandTech Scientific, $8.5 \mathrm{~mm}$ ) for UV measurement. SpectraMax M5 microplate reader from Molecular Devices was used to record the fluorescence intensity of antibody modified beads. $50 \mu \mathrm{L}$ modified beads with 200 $\mu \mathrm{L} 10 \mathrm{mM}$ Tris $\cdot \mathrm{HCl}$ buffer $\mathrm{pH} 8.0$ were mixed in Corning 96 well black polystyrene microplate for plate reader measurement. Bio-Rad Mini-PROTEAN Tetra Cell system was used for gel electrophoresis. ChemiDoc XRS+ Imaging system from Bio-Rad was used to detect and take images for the gel fluorescence.

\section{Methods}

\section{Synthesis of antibody-conjugate and antigen-conjugate}

Human IgG-Cy5, Protein A-Cy5 and HSA/BSA-TMR were all prepared using the same protocol. As a representative example, human $\mathrm{lgG}\left(4 \mathrm{mg}, 3 \times 10^{-8} \mathrm{~mol}\right)$ was dissolved in $1 \mathrm{~mL}$ 1X PBS pH 7.4, followed by addition of $150 \mu \mathrm{L} 1 \mathrm{mg} \cdot \mathrm{mL}^{-1} \mathrm{NIR}-641 \mathrm{~N}$-succinimidyl ester (Cy5NHS, $2.4 \times 10^{-7} \mathrm{~mol}, 8$ eq. relative to $\mathrm{lgG}$ ) in dimethyl sulfoxide. The mixture was incubated at dark for $2 \mathrm{~h}$ at $4{ }^{\circ} \mathrm{C}$. The sample was purified by PD-10 column using $1 \mathrm{X}$ PBS $\mathrm{pH} 7.4$ as eluent and the product absorbance was measured by UV-visible spectroscopy (UV/Vis (protein): $\lambda_{\max }(\varepsilon)=280 \mathrm{~nm}\left(210,000 \mathrm{M}^{-1} \mathrm{~cm}^{-1}\right)$; UVNis $(C y 5): \lambda_{\max }(\varepsilon)=633 \mathrm{~nm}\left(250,000 \mathrm{M}^{-1} \mathrm{~cm}^{-1}\right.$ in ethanol). The concentration of final product was determined by the calculation according to 
equation: $A=K \cdot I \cdot C$ ( $A$ is the sample absorbance, $K$ is the molar attenuation coefficient, $I$ is the path length of the beam of light through the material sample and $\mathrm{C}$ is the sample concentration). The purified conjugates were stored at $-20{ }^{\circ} \mathrm{C}$. Notice: in HSA/BSA-TMR preparation, less amount of TMR-NHS was added to achieve sub-stoichiometric modification.

\section{Preparation of $\mathrm{Ni}^{2+}$-NTA Sephacryl S200 beads}

$18.0 \mathrm{~g}$ Commercial Sephacryl $\mathrm{S} 200$ beads (swollen) was washed with $\mathrm{DI} \mathrm{H}_{2} \mathrm{O} 3$ times, following by adding $5.0 \mathrm{~mL}$ DI $\mathrm{H}_{2} \mathrm{O}, 2.0 \mathrm{~mL} 2 \mathrm{~mol} \cdot \mathrm{L}^{-1} \mathrm{NaOH}$ solution, $6.0 \mathrm{~mL}$ 1,4-butanediol diglycidyl ether and $50.0 \mathrm{mg}$ sodium borohydride. The mixture reacted at $4{ }^{\circ} \mathrm{C}$ overnight. After washing with $\mathrm{DI} \mathrm{H}_{2} \mathrm{O}$ and centrifuging, $5.0 \mathrm{mg} \mathrm{N}$-(5-amino-1-carboxypentyl) iminodiacetic acid (AB-NTA) and $7.8 \mathrm{mg}$ nickel chloride $\left(\mathrm{NiCl}_{2}\right)$ were dissolved into $5.0 \mathrm{~mL} 0.05 \mathrm{~mol} \cdot \mathrm{L}^{-1}$ borate buffer ( $\mathrm{pH}$ 8.5) and incubated with above beads overnight. Washing and centrifuging the beads at least 3 times with $\mathrm{DI} \mathrm{H}_{2} \mathrm{O}$, then the excess epoxy groups were quenched by reacting with $10 \mathrm{~mL} 1 \mathrm{~mol} \cdot \mathrm{L}^{-1}$ ethanolamine at r.t. for $2 \mathrm{~h}$. Afterwards, beads were washed with $\mathrm{DI} \mathrm{H}_{2} \mathrm{O}$ and stored at $4^{\circ} \mathrm{C}$.

\section{Preparation of thiol-Sepharose 6B beads with immunocomplex}

All thiol-Sepharose 6B-immunocomplexes were prepared using the same protocol. As a representative example, the thiopropyl-Sepharose 6B beads were swollen by suspending 1 $\mathrm{mL}$ dry bead powder to $5 \mathrm{~mL} \mathrm{DI} \mathrm{H}_{2} \mathrm{O}$ and incubated at r.t. for $6 \mathrm{~h}$. The hydrated beads were washed with $\mathrm{DI} \mathrm{H}_{2} \mathrm{O}$ and centrifuged. $10 \mathrm{mmol} \cdot \mathrm{L}^{-1}$ Tris(2-carboxyethyl) phosphine hydrochloride (TCEP) stock solution was prepared by dissolving TCEP $\left(28.7 \mathrm{mg}, 1 \times 10^{-3} \mathrm{~mol}\right)$ into $100 \mathrm{~mL} 10 \mathrm{mmol} \cdot \mathrm{L}^{-1}$ Tris- $\mathrm{HCl} \mathrm{pH} 8.0$ buffer. Then $5 \mathrm{mmol}, 2 \mathrm{mmol}, 1 \mathrm{mmol}, 0.5 \mathrm{mmol}, 0.2$ $\mathrm{mmol}$ and $0.1 \mathrm{mmol}$ TCEP solution was diluted by adding $5 \mathrm{~mL} 10 \mathrm{mmol} \cdot \mathrm{L}^{-1}$ TCEP stock solution into $5 \mathrm{~mL}, 20 \mathrm{~mL}, 45 \mathrm{~mL}, 95 \mathrm{~mL}, 245 \mathrm{~mL}$ and $495 \mathrm{~mL} 10 \mathrm{mmol}$ Tris-HCl pH 8.0 buffer respectively. Following this, $5 \mathrm{~mL} 0.1 \mathrm{mmol} \cdot \mathrm{L}^{-1}$ TCEP solution was added to activate the disulfide bond and release 2-thiolpyridine. After $1 \mathrm{~h}$ incubating, the beads were washed with $10 \mathrm{mmol} \cdot \mathrm{L}^{-1}$ Tris- $\mathrm{HCl} \mathrm{pH} 8.0$ buffer and divided into 20 aliquots. $20 \mu \mathrm{L} 2 \mathrm{mg} \cdot \mathrm{mL}^{-1}$ anti-human IgG-TRITC $\left(2.7 \times 10^{-10} \mathrm{~mol}\right)$ was diluted with $380 \mu \mathrm{L} 0.1 \mathrm{mmol} \cdot \mathrm{L}^{-1}$ TCEP solution to obtain 400 $\mu \mathrm{L} \quad 0.1 \mathrm{mg} \cdot \mathrm{mL}^{-1}$ activated anti-human IgG-TRITC solution, followed by incubating with activated beads at $4{ }^{\circ} \mathrm{C}$ for $1 \mathrm{~h}$. Then this anti-human IgG-TRITC solution and 1 aliquot bead were mixed and rotated gently at r.t. for $1 \mathrm{~h}$. The beads were washed with $10 \mathrm{mmol} \cdot \mathrm{L}^{-1}$ Tris$\mathrm{HCl} \mathrm{pH} 8.0$ buffer and centrifuged. $400 \mu \mathrm{L} 0.2 \mathrm{mg} \cdot \mathrm{mL}^{-1}\left(5.4 \times 10^{-10} \mathrm{~mol}, 2\right.$ eq. relative to antihuman IgG-TRITC) human IgG-FITC solution (40 $\mu \mathrm{L} 2 \mathrm{mg} \cdot \mathrm{mL}^{-1}$ human $\lg$ G-FITC in $360 \mu \mathrm{L} 10$ 
$\mathrm{mmol} \cdot \mathrm{L}^{-1}$ Tris- $\mathrm{HCl} \mathrm{pH} 8.0$ buffer) was incubated with beads for 10 min (or longer) at r.t. subsequently. The resulting beads were washed and then added with $1 \mathrm{~mL} 2 \mathrm{mmol} \cdot \mathrm{L}^{-1} \mathrm{TCEP}$ solution, which was gently agitated and left to incubate for $10 \mathrm{~min}$ (or longer). Afterwards, beads with immunocomplex were washed with $10 \mathrm{mmol} \cdot \mathrm{L}^{-1}$ Tris- $\mathrm{HCl} \mathrm{pH} 8.0$ buffer and all bead samples were characterized and analyzed with Zeiss confocal laser scanning microscopy. Z stacking scan was also performed to examine if the fluorescence signal was uniform in the beads (Figure S1). Note: 1) for Sepharose 6B-anti-lgG-alkaline phosphatase (AP) \& IgG system, the diluted ELF 97 substrate (50 $\mu$ L ELF 97 stock solution was dilute 20 times with 1X PBS pH 7.4 buffer) was added into the final TCEP treated bead samples and incubate for $1 \mathrm{~h}$, followed by wash/centrifugation, as shown in Figure S26, S27. For Sepharose 6B-anti-IgG-AP \& IgG-FITC system, the mixture of NBT and BCIP $(0.5 \mu L$ NBT stock solution added $0.5 \mu \mathrm{L} \mathrm{BCIP}$ stock solution and dilute 300 times with $10 \mathrm{mmol} \cdot \mathrm{L}^{-1}$ Tris$\mathrm{HCl}$ pH 8.0 buffer) substrate was added into bead samples and incubate for 5 min, followed by wash/centrifugation (Figure S28). NBT stock solution was prepared by dissolving $30 \mathrm{mg}$ NBT

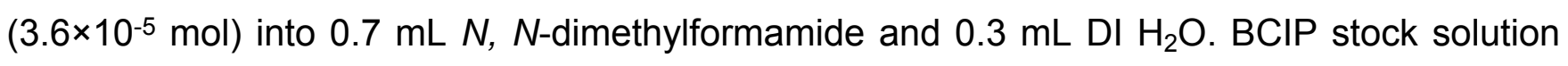
was prepared by dissolving $15 \mathrm{mg} \mathrm{BCIP}\left(3.5 \times 10^{-5} \mathrm{~mol}\right)$ into $1.0 \mathrm{~mL} \mathrm{~N}, N$-dimethylformamide. NBT and BCIP stock solution was stored separately at dark at $4{ }^{\circ} \mathrm{C}$. The mixed substrate solution was prepared and used freshly. 3) For SIGMAFAST Fast Red TR/Naphthol AS-MX substrate, 1 tablet was dissolved into $1 \mathrm{~mL} \mathrm{DI} \mathrm{H} \mathrm{H}_{2} \mathrm{O}$ to be used and $100 \mu \mathrm{L}$ substrate solution was added into each bead sample. 4) Dithiothreitol (DTT) is also effective at cleaving the disulfide bond (Figure S5). 5) Control groups, for example, beads reacted with anti-rabbit IgGAlexa532 and human IgG-Cy5 (Figure S8), bead reacted with monoclonal anti-actin IgG and actin (Figure S6), bead reacted with maleimide anti-lgG-Cy3 (Figure S4) were prepared with the same protocol as above described. 6) TCEP effect on different fluorescence probes were examined. $0.1 \mathrm{mg} \cdot \mathrm{mL}^{-1} \mathrm{lgG}-\mathrm{Cy} 3.5$, IgG-Cy5, anti-lgG-TRITC and IgG-FITC were dissolved in $1 \mathrm{mM}$ TCEP solution in $10 \mathrm{mM}$ Tris buffer, $\mathrm{pH} 8.0$ and stored at $4{ }^{\circ} \mathrm{C}$ for 1 week. UV-Vis spectrum before and after 1 week incubation was recorded and analyzed (Figure S3).

\section{Preparation of $\mathrm{Ni}^{2+}-\mathrm{NTA} 6 \mathrm{~B} / \mathrm{Ni}^{2+}-\mathrm{NTA}$ Sephacryl 200 beads with immunocomplex}

All $\mathrm{Ni}^{2+}-\mathrm{NTA}$ 6B/Ni ${ }^{2+}-\mathrm{NTA}$ Sephacryl S200 beads containing immunocomplex were prepared using the same protocol. As a representative example, $300 \mu \mathrm{L} \mathrm{Ni}{ }^{2+}-\mathrm{NTA} 6 \mathrm{~B}$ beads (swollen) were centrifuged to remove the supernatant and washed with $\mathrm{DI} \mathrm{H}_{2} \mathrm{O}$ (beads volume: $200 \mu \mathrm{L}$ ). $5 \mu \mathrm{L} 2 \mathrm{mg} \cdot \mathrm{mL}^{-1}$ Protein A-Cy5 $\left(2.8 \times 10^{-10} \mathrm{~mol}\right)$ was diluted with $95 \mu \mathrm{L} 10 \mathrm{mmol} \cdot \mathrm{L}^{-1} \mathrm{Tris}-\mathrm{HCl} \mathrm{pH}$ 8.0 buffer, followed by preincubating with $400 \mu \mathrm{L} 0.2 \mathrm{mg} \cdot \mathrm{mL}^{-1}\left(5.4 \times 10^{-10} \mathrm{~mol}\right)$ anti-human IgG- 
FITC solution $\left(40 \mu \mathrm{L} 2 \mathrm{mg} \cdot \mathrm{mL}^{-1}\right.$ human IgG-FITC in $360 \mu \mathrm{L} 10 \mathrm{mmol} \cdot \mathrm{L}^{-1}$ Tris-HCl pH 8.0 buffer). After $30 \mathrm{~min}$ incubation at $4{ }^{\circ} \mathrm{C}$, mixing the solution with $200 \mu \mathrm{L} \mathrm{Ni}{ }^{2+}-\mathrm{NTA}$ 6B beads and rotating gently at r.t. for $1 \mathrm{~h}$. After washing and centrifuging, the resulting beads were incubated with $400 \mu \mathrm{L} 0.2 \mathrm{mg} \cdot \mathrm{mL}^{-1}\left(5.4 \times 10^{-10} \mathrm{~mol}, 1\right.$ eq. relative to anti-human IgG-FITC) human IgG-TRITC solution ( $40 \mu \mathrm{L} 2 \mathrm{mg} \cdot \mathrm{mL}^{-1}$ human IgG-TRITC in $360 \mu \mathrm{L} 10 \mathrm{mmol} \cdot \mathrm{L}^{-1}$ Tris$\mathrm{HCl} \mathrm{pH} 8.0$ buffer), followed by washing with $10 \mathrm{mmol}$ Tris- $\mathrm{HCl} \mathrm{pH} 8.0$ buffer. $2.0 \mathrm{~mol}$ imidazole stock solution was prepared by dissolving imidazole (13.6 g, $0.2 \mathrm{~mol}$ ) into $100 \mathrm{~mL}$ $10 \mathrm{mmol} \cdot \mathrm{L}^{-1}$ Tris- $\mathrm{HCl} \mathrm{pH} 8.0$ buffer. Then $1.5 \mathrm{~mol} \cdot \mathrm{L}^{-1}, 1 \mathrm{~mol} \cdot \mathrm{L}^{-1}, 0.5 \mathrm{~mol} \cdot \mathrm{L}^{-1}$ and $0.2 \mathrm{~mol} \cdot \mathrm{L}^{-1}$ imidazole solution was diluted by adding $10 \mathrm{~mL} 2 \mathrm{~mol}$ imidazole stock solution into $3.3 \mathrm{~mL}, 10$ $\mathrm{mL}, 30 \mathrm{~mL}$ and $90 \mathrm{~mL} 10 \mathrm{mmol} \cdot \mathrm{L}^{-1} \mathrm{Tris}-\mathrm{HCl} \mathrm{pH} 8.0$ buffer respectively. Different concentration of imidazole solution was tested to cleave the above modified $\mathrm{Ni}^{2+}-\mathrm{NTA}-6 \mathrm{~B}$ beads and 0.5 $\mathrm{mol} \cdot \mathrm{L}^{-1}$ was chosen as the appropriate concentration for the subsequent experiment. All samples were characterized and analyzed with CLSM (Figure S17). Note: 1) Imidazole effect on Cy5 probe were examined as indicated in Figure S16. 2) For $\mathrm{Ni}^{2+}$-NTA Sephacryl $\mathrm{S} 200$ bead system, $0.2 \mathrm{~mol} \cdot \mathrm{L}^{-1}$ imidazole containing $0.1 \mathrm{~mol} \cdot \mathrm{L}^{-1} \mathrm{NaCl}$ solution shown the best cleavage efficiency with beads coupled with Protein A-Cy5. All Cy5 signal lost after imidazole treatment and thus this imidazole $+\mathrm{NaCl}$ solution was applied as the cleavage reagent in this system.

\section{Stability test of thiopropyl-Sepharose $6 \mathrm{~B} / \mathrm{Ni}^{2+}-\mathrm{NTA}$ 6B beads containing immunocomplex}

The preparation of thiopropyl-Sepharose $6 \mathrm{~B} / \mathrm{Ni}^{2+}-\mathrm{NTA} 6 \mathrm{~B}$ bead-immunocomplex was described as previously indicated. The beads were stored at $4{ }^{\circ} \mathrm{C}$ and the stability test was performed for 120 days. The CLSM was applied to determine the fluorescence intensity changes at Day 1, 2, 3, 5, 7, 10, 15, 20, 30, 40, 50, 60, 70, 80, 100 and 120 (Figure S2 and S18).

\section{Kinetic studies of thiopropyl-Sepharose 6B beads}

The reaction of thiopropyl-Sepharose 6B beads and anti-human IgG-TRITC (capture antibody)

$20 \mu \mathrm{L} 2 \mathrm{mg} \cdot \mathrm{mL}^{-1}$ anti-human IgG-TRITC $\left(2.7 \times 10^{-10} \mathrm{~mol}\right)$ was diluted with $380 \mu \mathrm{L} 0.1 \mathrm{mmol} \cdot \mathrm{L}^{-1}$ TCEP solution to obtain $400 \mu \mathrm{L} 0.1 \mathrm{mg} \cdot \mathrm{mL}^{-1}$ activated anti-human IgG-TRITC solution, followed by incubating at $4{ }^{\circ} \mathrm{C}$ for $1 \mathrm{~h}$. Following this, above anti-human IgG-TRITC solution and 1 aliquot TCEP pre-treated thiopropyl-Sepharose $6 \mathrm{~B}$ beads $(40 \mu \mathrm{L})$ were mixed and 
incubated at r.t. for $90 \mathrm{~min}$. During this period, the TRITC fluorescence intensity on beads ( $\geq 6$ beads) was monitored by CLSM at 0, 0.5, 1, 2, 3, 5, 8, 10, 15, 20, 25, 30, 40, 50, 60, 75 and 90 min. Kinetics were monitored in triplicate.

\section{The reaction of TCEP on capture antibody linked thiopropyl-Sepharose $6 B$ bead}

$10 \mu \mathrm{L}$ anti-human IgG-TRITC $\left(0.1 \mathrm{mg} \cdot \mathrm{mL}^{-1}\right)$ linked Sepharose 6B beads were incubated with $400 \mu \mathrm{L}$ different concentrations of TCEP $\left(0.1 \mathrm{mmol} \cdot \mathrm{L}^{-1}, 0.2 \mathrm{mmol} \cdot \mathrm{L}^{-1}, 0.5 \mathrm{mmol} \cdot \mathrm{L}^{-1}, 1 \mathrm{mmol} \cdot \mathrm{L}^{-1}\right.$, $2 \mathrm{mmol} \cdot \mathrm{L}^{-1}, 5 \mathrm{mmol} \cdot \mathrm{L}^{-1}$ and $\left.10 \mathrm{mmol} \cdot \mathrm{L}^{-1}\right)$ for $1 \mathrm{~h}$ at r.t. During this period, the TRITC fluorescence intensity on beads ( $\geq 6$ beads) was monitored by CLSM. Kinetics were monitored in triplicate.

The reaction of capture antibody coupled thiopropyl-Sepharose 6B bead with human IgG-FITC (target antigen)

$10 \mu \mathrm{L}$ anti-human IgG-TRITC linked Sepharose 6B beads were incubated with $400 \mu \mathrm{L}$ different concentrations of human IgG-FITC $\left(5 \mu \mathrm{g} \cdot \mathrm{mL}^{-1}, 10 \mu \mathrm{g} \cdot \mathrm{mL}^{-1}, 50 \mu \mathrm{g} \cdot \mathrm{mL}^{-1}\right.$ and 0.1 $\mathrm{mg} \cdot \mathrm{mL}^{-1}$ ) at r.t. for $2 \mathrm{~h}$. The FITC fluorescence intensity on beads ( $\geq 6$ beads) was monitored by CLSM during this period. Kinetics were performed in triplicate.

\section{The reaction of TCEP on thiopropyl-Sepharose $6 B$ bead containing capture antibody and} antigen complex

$10 \mu \mathrm{L}$ prepared beads-complex containing anti-human IgG-TRITC and IgG-FITC $\left(0.1 \mathrm{mg} \cdot \mathrm{mL}^{-1}\right.$, 1:1 eq.) was cleaved by $2 \mathrm{mmol}$ TCEP at r.t. for $1 \mathrm{~h}$. Both TRITC and FITC fluorescence intensity changes on beads ( $\geq 6$ beads) were monitored by CLSM during this period. Kinetics were performed in triplicate.

\section{Quantitative analysis of fluorescence intensity of beads coupled with different concentrations of antibodies and antigens}

The quantification of fluorescence intensities of thiopropyl-Sepharose $6 \mathrm{~B}$ beadimmunocomplex and $\mathrm{Ni}^{2+}$-NTA $6 \mathrm{~B}$ bead-immunocomplex were analyzed with the same protocol. As a representative example, thiopropyl-Sepharose 6B bead modified with different concentrations of capture antibody anti-human IgG-TRITC and antigen human IgG-FITC (1:1 eq.) were prepared using the same protocol as described previouly. $400 \mu \mathrm{L} 1.0 \mathrm{mg} \cdot \mathrm{mL}^{-1}, 0.8$ 
$\mathrm{mg} \cdot \mathrm{mL}^{-1}, 0.6 \mathrm{mg} \cdot \mathrm{mL}^{-1}, 0.5 \mathrm{mg} \cdot \mathrm{mL}^{-1}, 0.4 \mathrm{mg} \cdot \mathrm{mL}^{-1}, 0.3 \mathrm{mg} \cdot \mathrm{mL}^{-1}, 0.2 \mathrm{mg} \cdot \mathrm{mL}^{-1}, 0.1 \mathrm{mg} \cdot \mathrm{mL}^{-1}, 50$ $\mu \mathrm{g} \cdot \mathrm{mL}^{-1}, 40 \mu \mathrm{g} \cdot \mathrm{mL}^{-1}, 30 \mu \mathrm{g} \cdot \mathrm{mL}^{-1}, 20 \mu \mathrm{g} \cdot \mathrm{mL}^{-1}, 10 \mu \mathrm{g} \cdot \mathrm{mL}^{-1}, 5 \mu \mathrm{g} \cdot \mathrm{mL}^{-1}, 2.5 \mu \mathrm{g} \cdot \mathrm{mL}^{-1}, 1 \mu \mathrm{g} \cdot \mathrm{mL}^{-1}$, $0.5 \mu \mathrm{g} \cdot \mathrm{mL}^{-1}, 0.25 \mu \mathrm{g} \cdot \mathrm{mL}^{-1}, 0.1 \mu \mathrm{g} \cdot \mathrm{mL}^{-1}, 50 \mathrm{ng} \cdot \mathrm{mL}^{-1}, 25 \mathrm{ng} \cdot \mathrm{mL}^{-1}, 10 \mathrm{ng} \cdot \mathrm{mL}^{-1}, 5 \mathrm{ng} \cdot \mathrm{mL}^{-1}, 1$ $\mathrm{ng} \cdot \mathrm{mL}^{-1}$ anti-human IgG-TRITC were incubated with beads for $1 \mathrm{~h}$, followed by reacting with $400 \mu \mathrm{L} 20 \mathrm{mmol} \cdot \mathrm{L}^{-1}$ quench reagent $\left(\mathrm{NH}_{2}\right.$-PEG-Mal) for $1 \mathrm{~h}$. All quench reagents (Nhydroxyethyl-Mal, NHS-PEG-Mal, Mal-PEG-Mal, $\mathrm{NH}_{2}$-PEG-Mal, alkyne-PEG-Mal and 4 armPEG-Mal, $400 \mu \mathrm{L} 20 \mathrm{mmol} \cdot \mathrm{L}^{-1}$ ) were incubated with beads previously and $\mathrm{NH}_{2}-\mathrm{PEG}-$ Mal possessed the best performance to decrease the fluorescence signal loss than the others. Therefore, $\mathrm{NH}_{2}$-PEG-Mal as quench reagent was applied in the following preparation of thiolSepharose 6B beads-complexes. Next, the washed bead reacted with corresponding concentration of human IgG-FITC respectively. All sample fluorescence intensities were characterized and analyzed with CLSM (with same parameter) and Image J program. Then 2 $\mathrm{mmol} \cdot \mathrm{L}^{-1}$ TCEP solution was gently added into each bead sample and left to incubate for 30 min under agitation. The fluorescence intensities were recorded with CLSM (with same parameter). Note: with the lower antibody concentration, the stronger laser power, larger gain value and pinhole value were necessary during the CLSM measurement. After each time of changing parameter, the last sample of each group was measured with new parameter again for calculation use. The CLSM images and quantification of fluorescence intensities can be found in Figure S10-S12, S19 and S20. Each range was detected with the same CLSM parameter.

\section{Quantitative analysis of mixture of beads containing different concentrations of capture antibodies and antigens}

The quantitative analysis of mixed beads samples was analyzed with the same protocol. As a representative example, 4 tubes of $5 \mu \mathrm{L}$ thiopropyl-Sepharose $6 \mathrm{~B}$ beads were modified with 4 concentrations $\left(1.0 \mathrm{mg} \cdot \mathrm{mL}^{-1}, 0.5 \mathrm{mg} \cdot \mathrm{mL}^{-1}, 0.2 \mathrm{mg} \cdot \mathrm{mL}^{-1}\right.$ and $\left.50 \mu \mathrm{g} \cdot \mathrm{mL}^{-1}\right)$ of capture antibody anti-human IgG-TRITC and antigen human IgG-FITC (1:1 eq.), as described previously. Then the beads-complexes were mixed gently and analyzed with CLSM (Figure S9). Bead number and fluorescence intensity were calculated.

The measurement of thiopropyl-Sepharose 6B bead size distribution and beadsimmunocomplex fluorescence intensity distribution

Thiopropyl-Sepharose 6B bead-complex consists of anti-human IgG-TRITC and human IgGCy5 (1:1 eq.) with 4 concentrations $\left(0.1 \mathrm{mg} \cdot \mathrm{mL}^{-1}, 50 \mu \mathrm{g} \cdot \mathrm{mL}^{-1}, 10 \mu \mathrm{g} \cdot \mathrm{mL}^{-1}\right.$ and $\left.1 \mu \mathrm{g} \cdot \mathrm{mL}^{-1}\right)$ were 
prepared as previously described. Then, CLSM images of each kind of beads were analyzed for calculation of bead size distribution (1000 beads) and fluorescence intensity distribution (500 beads for each concentration). The bead size distribution and fluorescence intensity distribution of beads with different antibody concentrations can be found in Figure S13 and S14.

\section{The calculation of amount of antibody and antigen molecules modified on individual bead}

The calculation of the average number of capture antibody and antigen modified on individual bead was performed with the same protocol. As a representative example, the thiopropylSepharose $6 \mathrm{~B}$ beads were swollen by suspending $1 \mathrm{~mL}$ dry bead powder to $5 \mathrm{~mL} \mathrm{DI} \mathrm{H}_{2} \mathrm{O}$ and incubated at r.t. The hydrated beads were washed with $\mathrm{DI} \mathrm{H}_{2} \mathrm{O}$ and centrifuged. $50 \mu \mathrm{L} 2$ $\mathrm{mg} \cdot \mathrm{mL}^{-1}$ anti-human IgG-TRITC $\left(6.6 \times 10^{-10} \mathrm{~mol}\right)$ was diluted with $450 \mu \mathrm{L} 0.1 \mathrm{mmol} \cdot \mathrm{L}^{-1} \mathrm{TCEP}$ solution to obtain $500 \mu \mathrm{L} 0.2 \mathrm{mg} \cdot \mathrm{mL}^{-1}$ activated anti-human IgG-TRITC solution with the UV absorbance of 0.15787 at $555 \mathrm{~nm} .40 \mu \mathrm{L}$ swelling beads was then added into above activated anti-human IgG-TRITC solution and incubated at $4{ }^{\circ} \mathrm{C}$ for $1 \mathrm{~h}$. According to the sphere volume formula, the average bead volume can be calculated as $5.2 \times 10^{-13} \mathrm{~m}^{3}$ and the bead number is about $7.7 \times 10^{4}$ in $40 \mu \mathrm{L}$ swelling beads, as the average bead diameter is about $100 \mu \mathrm{m}$. After 1 $\mathrm{h}$ incubation, the supernatant UV absorbance at $555 \mathrm{~nm}$ was about 0.08742 , which means the capture antibody on the bead was saturated and about $3.0 \times 10^{-10} \mathrm{~mol}$ anti-IgG-TRITC coupled to the beads. $500 \mu \mathrm{L} 0.4 \mathrm{mg} \cdot \mathrm{mL}^{-1}$ human lgG-FITC solution was prepared by mixing $10 \mu \mathrm{L} 20$ $\mathrm{mg} \cdot \mathrm{mL}^{-1}$ human IgG-FITC $\left(1.3 \times 10^{-9} \mathrm{~mol}, 2 \mathrm{eq}\right.$. of anti-human IgG-TRITC) solution with $490 \mu \mathrm{L}$ $10 \mathrm{mmol} \cdot \mathrm{L}^{-1}$ Tris- $\mathrm{HCl} \mathrm{pH} 8.0$ buffer and its UV absorbance was recorded as 0.42127 at 495 $\mathrm{nm}$. After $1 \mathrm{~h}$ incubation of above beads with human IgG-FITC solution, the supernatant UV absorbance was about 0.24724 at $495 \mathrm{~nm}$, indicating about $5.5 \times 10^{-10}$ mol target molecules were captured on $40 \mu \mathrm{L}$ beads. As Avogadro constant is $6.022 \times 10^{-23} \mathrm{~mol}^{-1}$, the number of antihuman IgG-TRITC/ human IgG-FITC reacted on $40 \mu \mathrm{L}$ swelling beads was calculated as $1.8 \times 10^{14}$. Therefore, the number of anti-human IgG-TRITC/human IgG-FITC reacted on a single bead are about $2.35 \times 10^{9}$ and $4.34 \times 10^{9}$. In this case, the model capture antibody and antigen molecules were both saturated on the Sepharose beads, so the loading capacity of the model capture antibody and antigen on single bead are about $2.35 \times 10^{9}$ and $4.34 \times 10^{9}$.

\section{Multiplexed detection of target molecules in single beads}


ICEA platform for multiplexed detection of target molecules in single Ni ${ }^{2+}$-NTA Sephacryl S200 beads was prepared as follows. $0.3 \mathrm{~mL} \mathrm{Ni}^{2+}-\mathrm{NTA} 6 \mathrm{~B}$ beads were incubated with $100 \mu \mathrm{L} 0.2$ $\mathrm{mg} \cdot \mathrm{mL}^{-1}$ Protein A-Cy5 $\left(2.8 \times 10^{-10} \mathrm{~mol}\right.$, in $10 \mathrm{mmol} \cdot \mathrm{L}^{-1}$ Tris-HCl pH 8.0 buffer $)$ for $1 \mathrm{~h}$, followed by incubating with $400 \mu \mathrm{L}$ mixture of capture antibodies containing $40 \mu \mathrm{L} 2 \mathrm{mg} \cdot \mathrm{mL}^{-1}$ anti-KLC IgG-FITC $\left(5.4 \times 10^{-10} \mathrm{~mol}\right)$ and $40 \mu \mathrm{L} 2 \mathrm{mg} \cdot \mathrm{mL}^{-1}$ anti-HSA IgG $\left(5.4 \times 10^{-10} \mathrm{~mol}\right)$. After $1 \mathrm{~h}$ incubation at $4{ }^{\circ} \mathrm{C}$, the resulting beads were washed and incubated with $400 \mu \mathrm{L}$ mixture of target solution containing $40 \mu \mathrm{L} 2 \mathrm{mg} \cdot \mathrm{mL}^{-1} \mathrm{KLC}\left(3.2 \times 10^{-9} \mathrm{~mol}\right)$ and $40 \mu \mathrm{L} 2 \mathrm{mg} \cdot \mathrm{mL}^{-1} \mathrm{HSA}-$ $\operatorname{TMR}\left(1.2 \times 10^{-9} \mathrm{~mol}\right)$. Then different concentration of imidazole solution was tested to cleave the above modified $\mathrm{Ni}^{2+}-\mathrm{NTA}-6 \mathrm{~B}$ beads and $0.2 \mathrm{~mol} \cdot \mathrm{L}^{-1}$ imidazole dissolved in $0.1 \mathrm{~mol} \cdot \mathrm{L}^{-1} \mathrm{NaCl}$ solution performed best cleavage efficiency. The fluorescence intensities of beads-complexes were examined and analyzed by CLSM (Figure S23).

\section{SDS-PAGE test of thiopropyl-Sepharose 6B bead-immunocomplex consists of anti-HSA IgG and HSA-TMR}

Beads-anti HSA IgG, beads-anti-HSA IgG \& HSA-TMR (pre- and post- TCEP cleavage) were prepared as previously described. $20 \mu \mathrm{L}$ bead sample was mixed with $20 \mu \mathrm{L}$ sample buffer (19 $\mu \mathrm{L}$ Laemmli Sample Buffer and $1 \mu \mathrm{L}$ 2-mercaptoethanol) respectively. The mixture was denatured at $98{ }^{\circ} \mathrm{C}$ for 10 min using a heat block, and then $25 \mu \mathrm{L}$ sample and $8 \mu \mathrm{L}$ PageRuler prestained protein ladder (10 to $180 \mathrm{kDa}$ ) were loaded into a $10 \%$ acrylamide gel for the SDSPAGE analysis (60 $\mathrm{v}$ and $120 \mathrm{v}$, in $1 \mathrm{X}$ Tris/Glycine/SDS buffer).Separating gel was made of $37.3 \% \mathrm{DI} \mathrm{H} \mathrm{H}_{2} \mathrm{O}, 26.1 \% 1.5 \mathrm{~mol} \cdot \mathrm{L}^{-1}$ Tris- $\mathrm{HCl} \mathrm{pH} 8.8,34.8 \%$ acrylamide/bis solution (30\%, 29:1), $1 \%$ SDS ( $10 \%$ solution), $0.7 \%$ APS ( $10 \%$ solution) and $0.075 \%$ TEMED. Stacking gel was made of $65.3 \% \mathrm{DI} \mathrm{H} \mathrm{H}_{2} \mathrm{O}, 13.0 \% 1.0 \mathrm{~mol} \cdot \mathrm{L}^{-1} \mathrm{Tris}-\mathrm{HCl} \mathrm{pH} 6.8,19.6 \%$ acrylamide/bis solution (30\%, 29:1), $1.2 \%$ SDS (10\% solution), $0.78 \%$ APS (10\% solution) and $0.12 \%$ TEMED. A fluorescent image of the gel was recorded with a ChemiDoc Image system (Bio-Rad). Coomassie brilliant blue R-250 staining solution was used to stain the proteins for 40 min and a destaining solution ( $30 \%$ methanol, $10 \%$ acetic acid) was then used until the gel gave the appropriate stained bands by changing the destaining solution several times (Figure S7).

\section{Urine tests with thiopropyl-Sepharose 6B bead coupled with capture antibody anti-lgG- TRITC}

Thiopropyl-Sepharose $6 \mathrm{~B}$ bead containing anti-human IgG-TRITC $\left(0.5 \mathrm{mg} \cdot \mathrm{mL}^{-1}\right)$ were prepared as previously described. Then the beads were quenched with $\mathrm{NH}_{2}$-PEG-Mal, as described in previously. The urine sample was obtained from human subjects and the 
supernatant was assayed after centrifugation. Urine with different concentrations of human $\operatorname{lgG}\left(0.5 \mathrm{mg} \cdot \mathrm{mL}^{-1}, 0.1 \mathrm{mg} \cdot \mathrm{mL}^{-1}, 50 \mu \mathrm{g} \cdot \mathrm{mL}^{-1}, 10 \mu \mathrm{g} \cdot \mathrm{mL}^{-1}, 1 \mu \mathrm{g} \cdot \mathrm{mL}^{-1}, 0.1 \mu \mathrm{g} \cdot \mathrm{mL}^{-1}, 10 \mathrm{ng} \cdot \mathrm{mL}^{-1}, 1\right.$ $\mathrm{ng} \cdot \mathrm{mL}^{-1}$ and $0 \mathrm{ng} \cdot \mathrm{mL}^{-1}$ ) was prepared by diluting $0.5 \mathrm{mg} \cdot \mathrm{mL}^{-1} \mathrm{lgG}$-urine stock solution with urine supernatant respectively. The same volume of beads was added into urine samples containing different concentrations of $\lg G$ and incubated for $1 \mathrm{~h}$. After wash/centrifugation, beads were treated with $2 \mathrm{mM}$ TCEP solution for $30 \mathrm{~min}$. Afterwards, beads with immunocomplex were washed with $10 \mathrm{mmol} \cdot \mathrm{L}^{-1}$ Tris- $\mathrm{HCl} \mathrm{pH} 8.0$ buffer and characterized with CLSM. The data was analyzed with Image $\mathrm{J}$ program (Figure S24). Note: 1 ). It is necessary to increase the laser power and gain value to observe the bright TRITC signal of samples with less antibody molecules in CLSM measurement. After changing the parameter, the last sample of last group was measured with new parameter again for calculation use. 2). The TRITC fluorescence intensity of TCEP treated beads reacted with $0 \mathrm{mg} \cdot \mathrm{mL}^{-1} \mathrm{IgG}$-urine was regarded as the background and the background was deleted for all samples in the analysis process.

\section{Urine tests with $\mathrm{Ni}^{2+}$-NTA Sephacryl $\mathbf{S} 200$ bead coupled with capture antibody anti-KLC IgG-FITC}

$\mathrm{Ni}^{2+}$-NTA Sephacryl S200 bead containing Protein A-Cy5 $\left(0.5 \mathrm{mg} \cdot \mathrm{mL}^{-1}\right)$, anti-KLC IgG-FITC $\left(0.5 \mathrm{mg} \cdot \mathrm{mL}^{-1}\right)$ were prepared as previously described. The urine sample was obtained from human subjects and the supernatant was assayed after centrifugation. Urine with different concentrations of $\mathrm{KLC}\left(0.5 \mathrm{mg} \cdot \mathrm{mL}^{-1}, 0.2 \mathrm{mg} \cdot \mathrm{mL}^{-1}, 0.1 \mathrm{mg} \cdot \mathrm{mL}^{-1}, 50 \mu \mathrm{g} \cdot \mathrm{mL}^{-1}, 10 \mu \mathrm{g} \cdot \mathrm{mL}^{-1}, 5\right.$ $\mu \mathrm{g} \cdot \mathrm{mL}^{-1}, 1 \mu \mathrm{g} \cdot \mathrm{mL}^{-1}, 0.1 \mu \mathrm{g} \cdot \mathrm{mL}^{-1}$ and $0 \mathrm{ng} \cdot \mathrm{mL}^{-1}$ ) was prepared by diluting $0.5 \mathrm{mg} \cdot \mathrm{mL}^{-1} \mathrm{KLC}-$ urine stock solution with urine supernatant respectively. The same volume of beads was added into urine samples containing different concentrations of KLC and incubated for $1 \mathrm{~h}$. After wash/centrifugation, beads were treated with $0.5 \mathrm{M}$ imidazole solution for $30 \mathrm{~min}$. Afterwards, beads with immunocomplex were washed with $10 \mathrm{mmol} \cdot \mathrm{L}^{-1}$ Tris- $\mathrm{HCl} \mathrm{pH} 8.0$ buffer and characterized with CLSM. The data was analyzed with Image J program (Figure S25). Note: 1). The FITC fluorescence intensity of imidazole treated beads reacted with $0 \mathrm{mg} \cdot \mathrm{mL}^{-1}$ KLC-urine was regarded as the background and the background was deleted for all samples in the analysis process. 


\section{Supporting Figures}

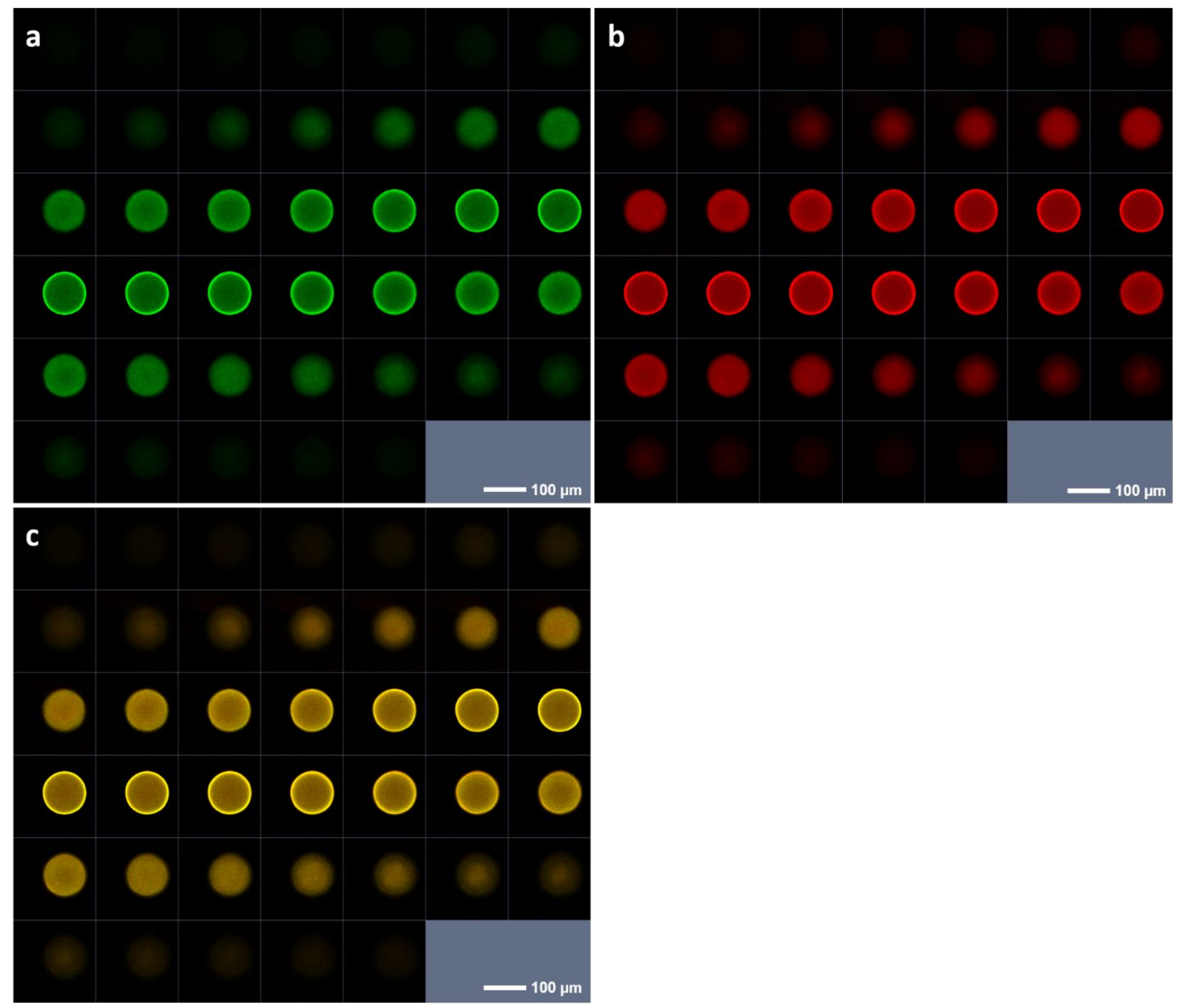

Figure S1. CLSM images of Sepharose 6B coupled with anti-IgG-TRITC and target IgG-FITC with Z-stack scanning (40 slices). a) TRITC channel. b) FITC channel. c) Merged images of multi-channels (TRITC and FITC). Scale bar, $100 \mu \mathrm{m}$. 
Sepharose 6B beads + anti-human IgG-TRITC \& human IgG-Cy5
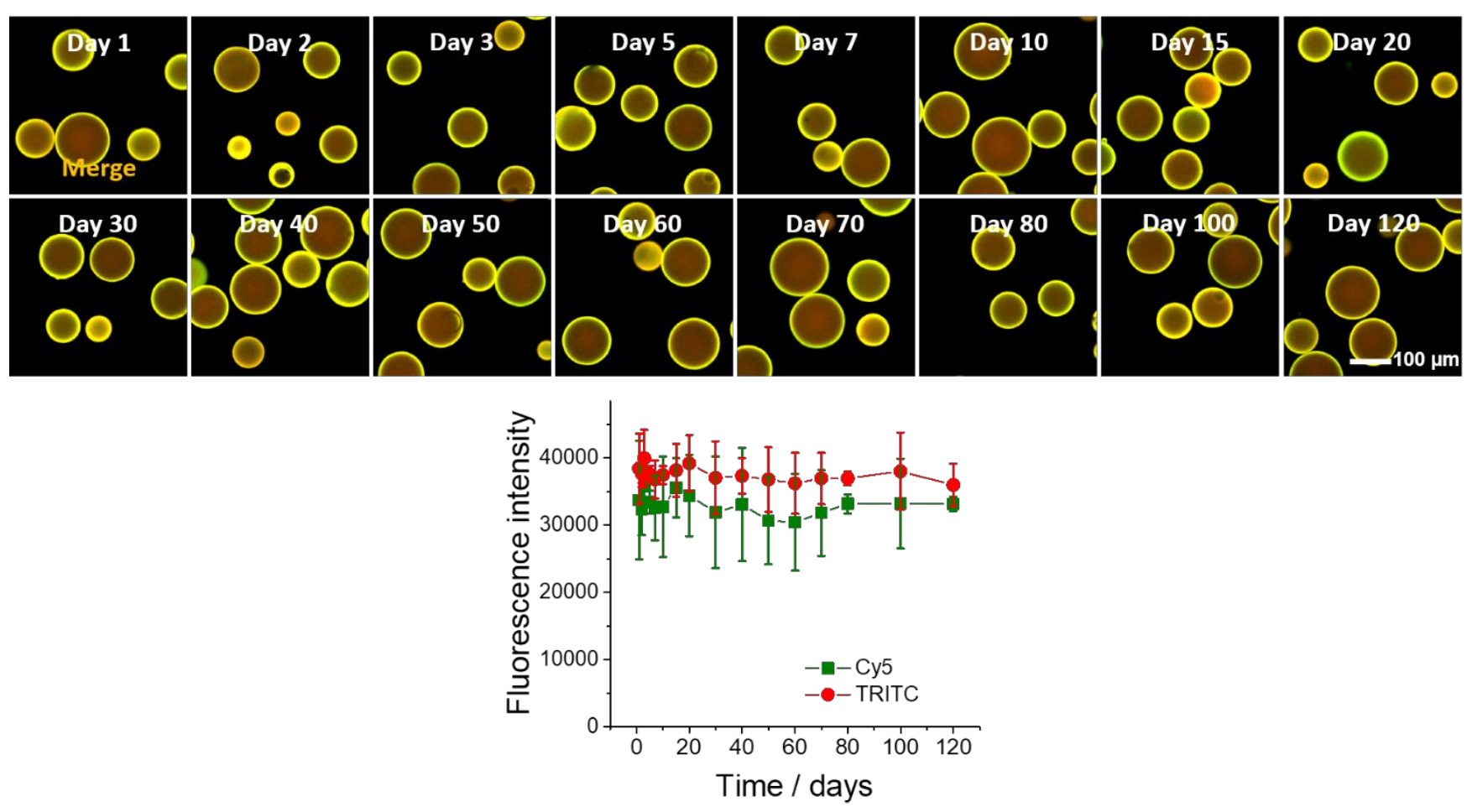

Figure S2. Stability test of thiopropyl-Sepharose 6B beads modified with capture antibody anti-human IgG-TRITC and antigen human IgG-Cy5 (0-120 days). Merge: Cy5 channel-green, TRITC channel-red. Error bars represent the standard deviation of triplicate measurements. Scale bar, $100 \mu \mathrm{m}$. 

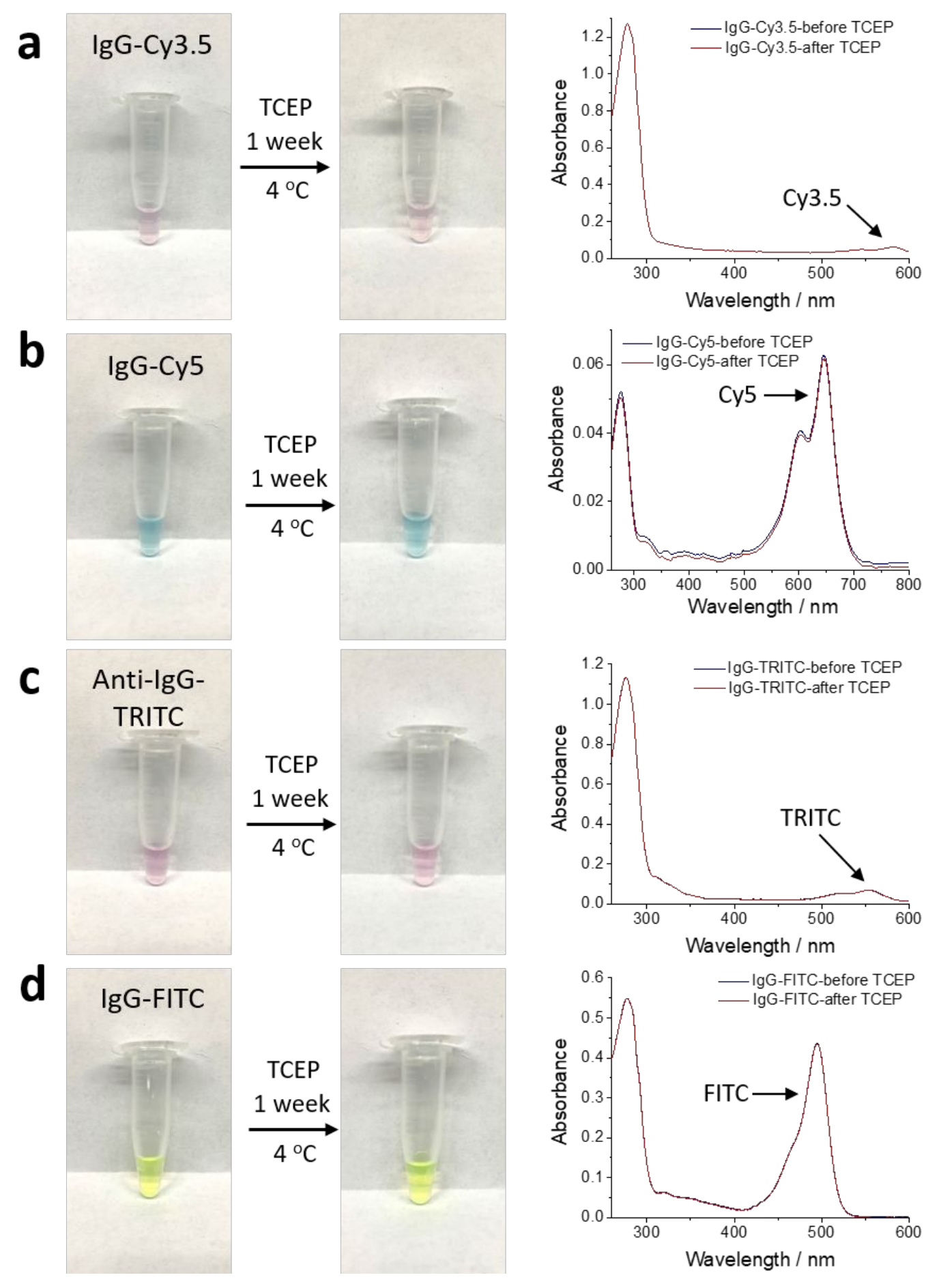

Figure S3. TCEP effect on different fluorescence probes and UV-Vis spectrum before and after TCEP incubation. a) IgG-Cy3.5. b) IgG-Cy5. c) anti-lgG-TRITC. d) IgG-FITC. 

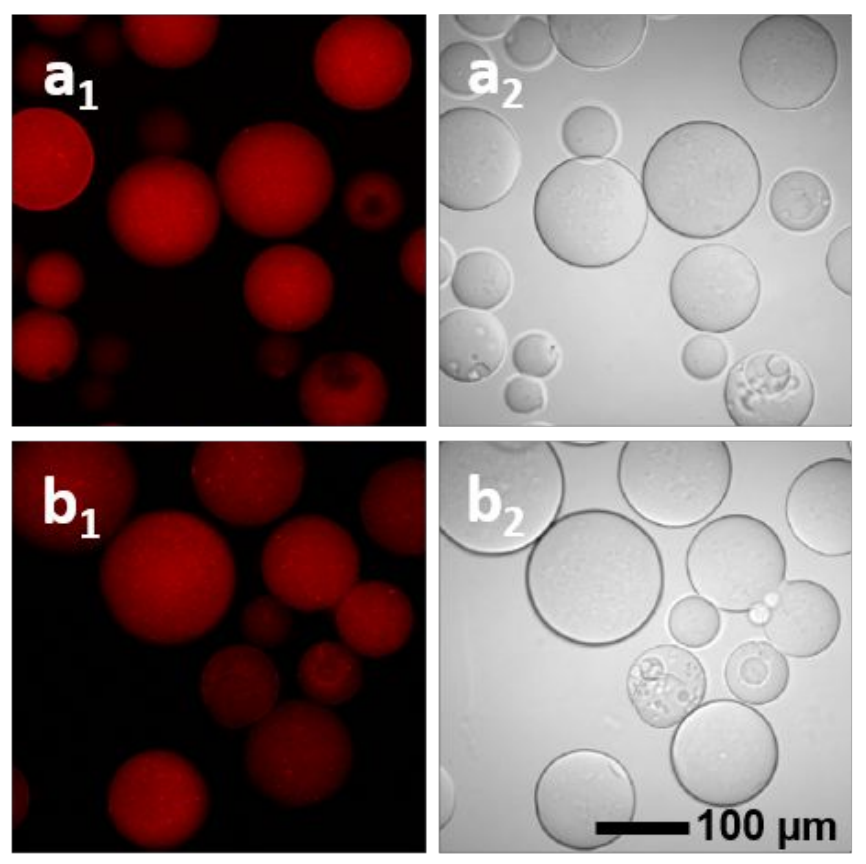

Figure S4. CLSM images of thiopropyl-Sepharose 6B bead reacted with maleimide-anti-lgGCy3 (Cy3 channel and bright field images). $a_{1}, a_{2}$ ) Before TCEP treatment. $b_{1}, b_{2}$ ) After TCEP treatment. Scale bar, $100 \mu \mathrm{m}$. 
Sepharose 6B Beads + anti-human IgG-TRITC \& human IgG-FITC

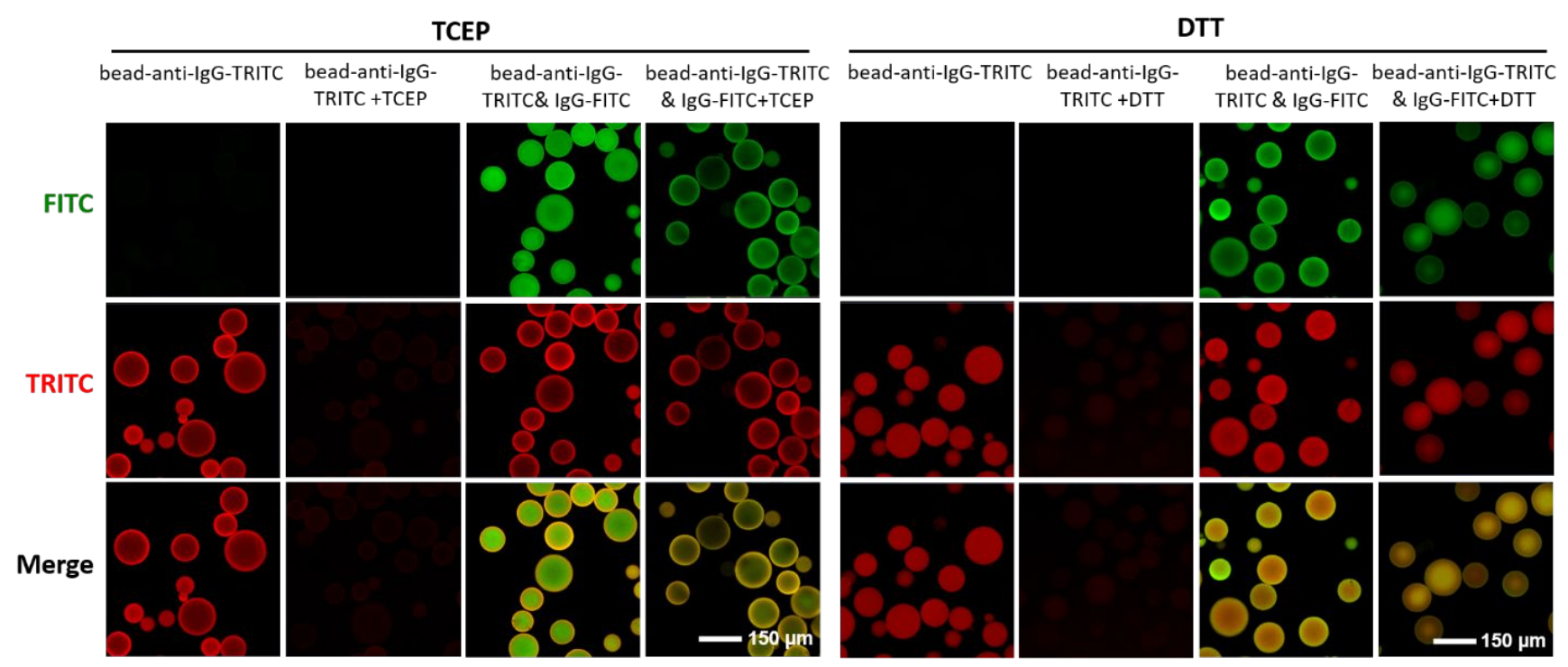

Figure S5. Confocal laser scanning microscope images of thiopropyl-Sepharose 6B bead coupled with anti-human IgG-TRITC and human IgG-FITC cleaved by $2 \mathrm{mM}$ Tris(2carboxyethyl) phosphine hydrochloride (TCEP) and DL-dithiothreitol (DTT). Scale bar, $150 \mu \mathrm{m}$. 

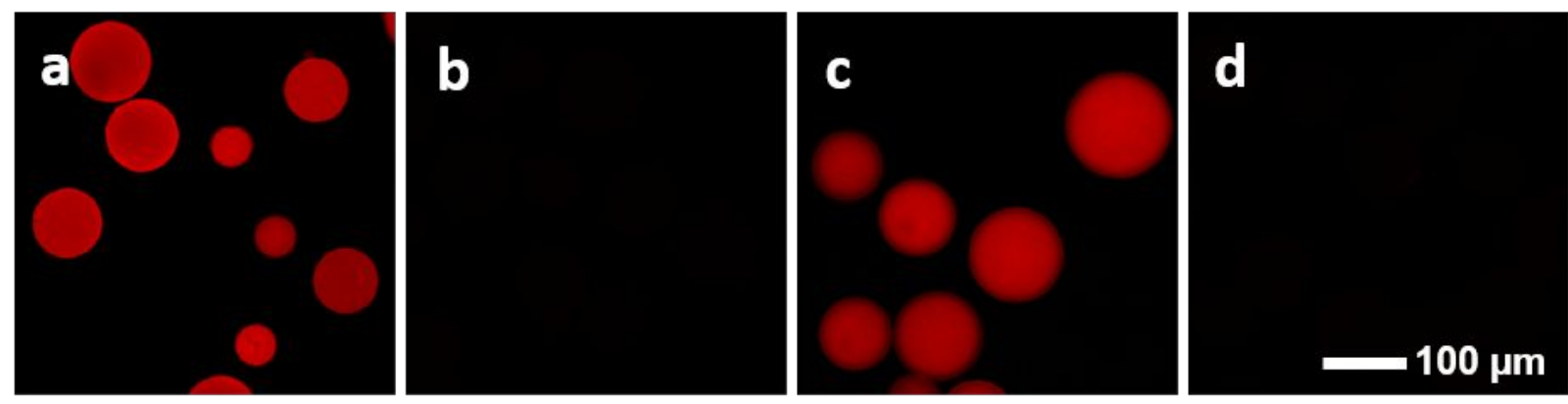

Figure S6. CLSM images of thiopropyl-Sepharose 6B bead reacted with monoclonal-anti actin-IgG-Cy3. a) Bead modified with anti actin IgG-Cy3. b) Bead-anti actin IgG-Cy3 cleaved by TCEP. c) Bead coupled with anti actin IgG-Cy3 and actin. d) bead coupled with anti actin IgG-Cy3 and actin followed by TCEP treatment. Scale bar, $100 \mu \mathrm{m}$. 


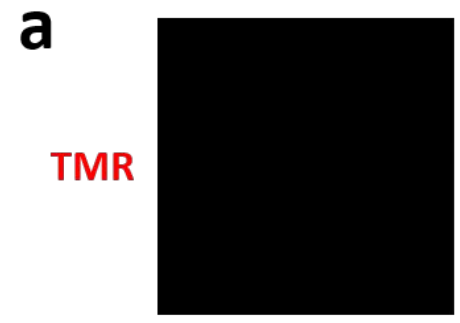

Bead-anti HSA IgG Bead-anti HSA IgG + TCEP

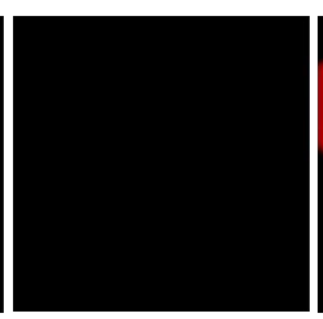

Bead-HSA-TMR

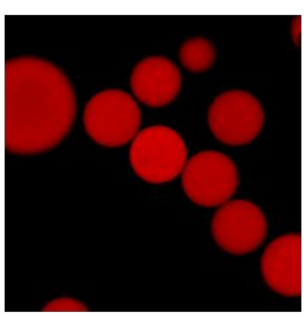

Bead-anti HSA IgG +HSA-TMR

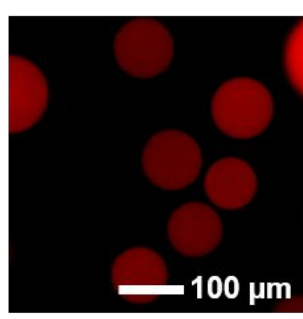

Bead-anti HSA IgG + HSA-TMR + TCEP

b

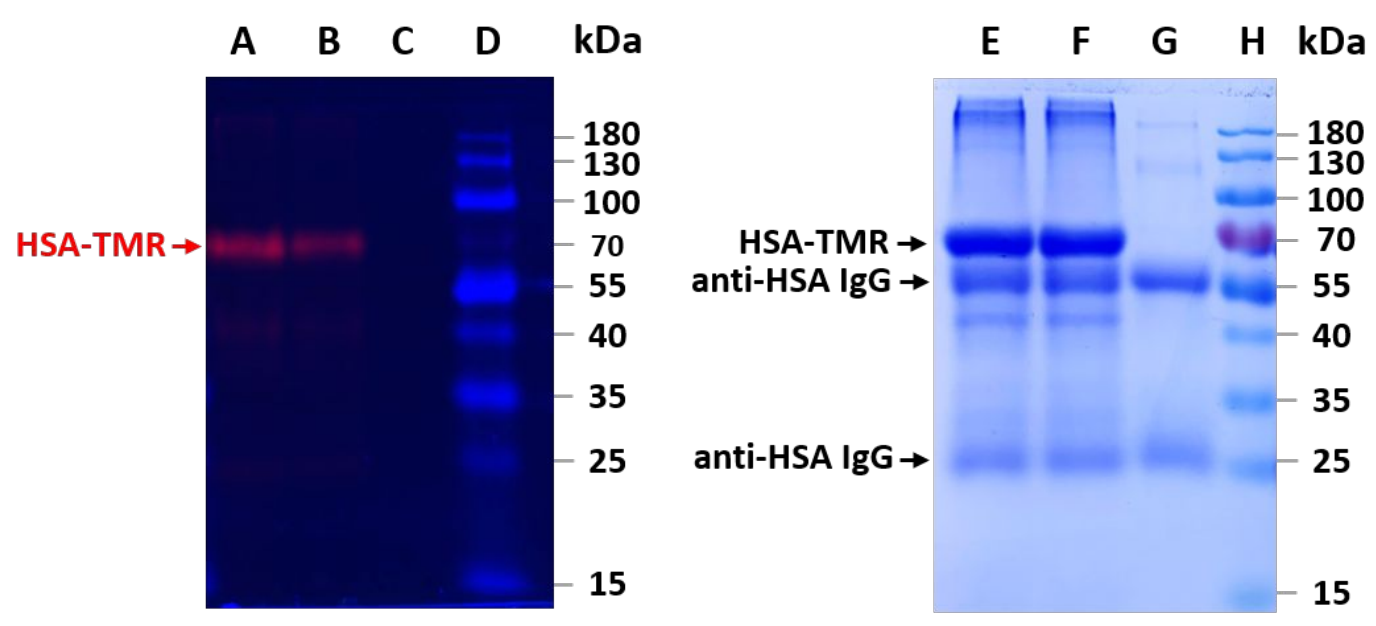

Figure S7. Characterization of thiopropyl-Sepharose 6B beads coupled with capture antibody (anti-human albumin $\lg G$ ) and antigen (human serum albumin-TMR (HSA-TMR)). a) CLSM images of bead-capture antibody and bead-complexes before/after TCEP treatment. b) In-gel fluorescence signals (left panel) and Coomassie blue staining SDS PAGE gel (right panel) of thiopropyl-Sepharose 6B beads containing anti-HSA IgG \& HSA-TMR. (C and D refer to the beads modified with anti-HSA IgG, B and F are beads-anti-HSA IgG + HSA-TMR, A and E are beads-anti-HSA IgG \& HSA-TMR + TCEP cleavage, $D$ and $H$ are prestained protein standard (15 kDa-180 kDa). Scale bar, $100 \mu \mathrm{m}$. 


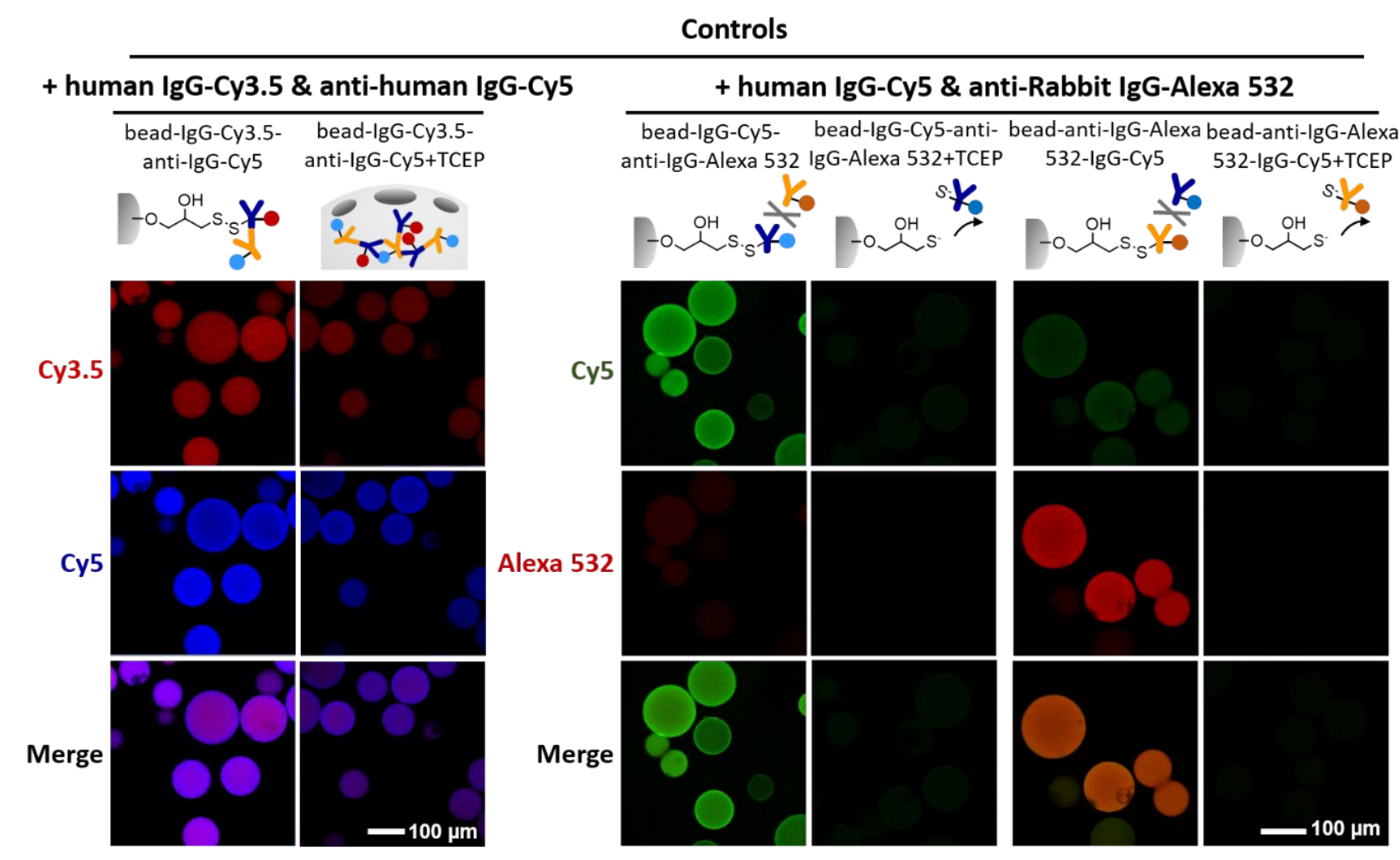

Figure S8. CLSM images of thiopropyl-Sepharose 6B bead control groups which reacted with human IgG-Cy3.5 \& anti-human IgG-Cy5 and human IgG-Cy5 \& anti-rabbit IgG-Alexa 532. Scale bar, $100 \mu \mathrm{m}$. 

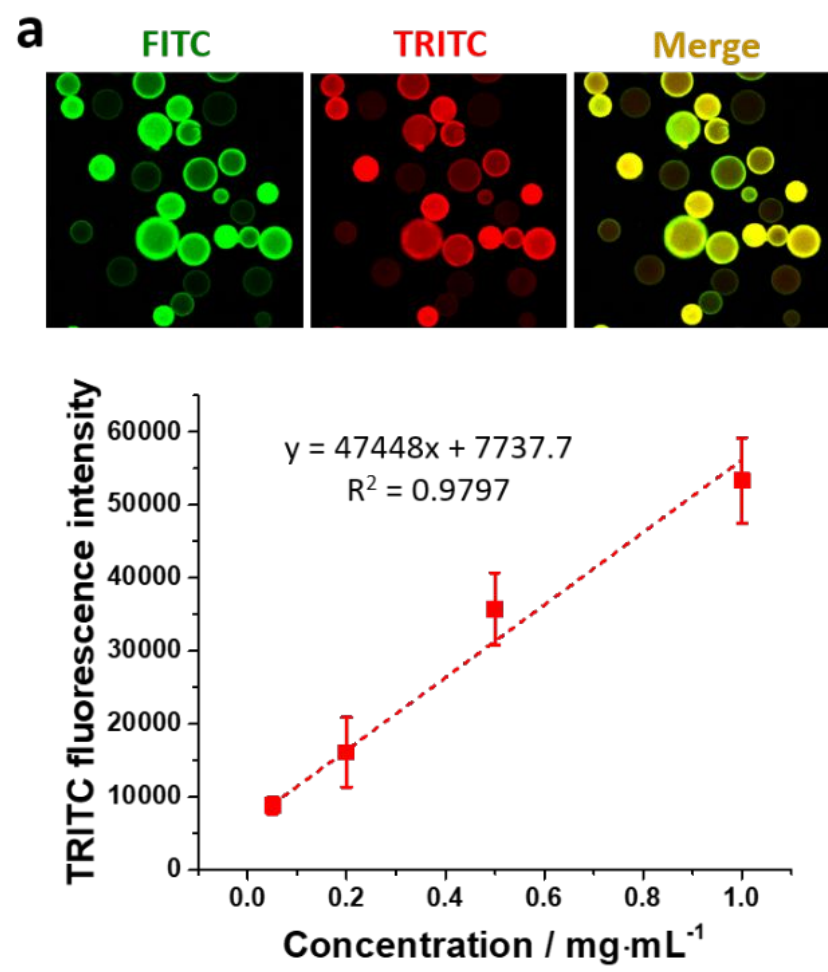
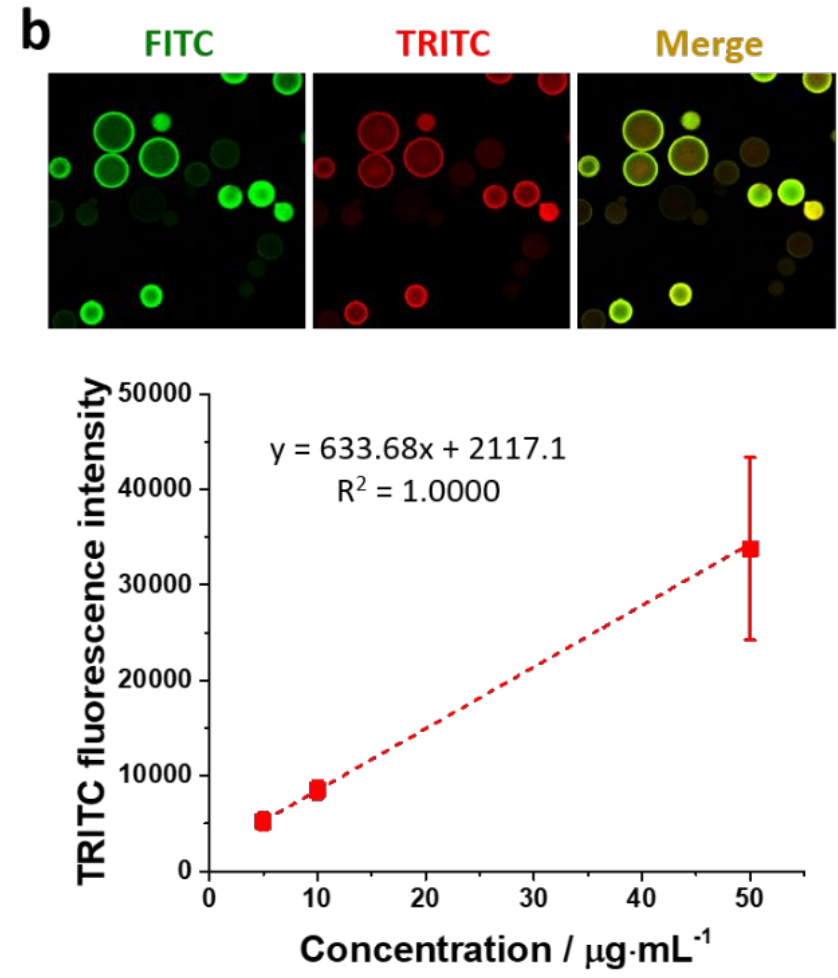

Figure S9. CLSM images and quantitative analysis of mixed thiopropyl-Sepharose 6B beadanti-human IgG-TRITC \& human IgG-FITC (1:1 eq.) samples. a) Mixture with 4 concentrations of beads (1.0 mg. mL $\mathrm{m}^{-1}, 0.5 \mathrm{mg} \cdot \mathrm{mL}^{-1}, 0.2 \mathrm{mg} \cdot \mathrm{mL}^{-1}$ and $\left.50 \mu \mathrm{g} \cdot \mathrm{mL}^{-1}\right)$. b) Mixture with 3 concentrations of beads $\left(50 \mu \mathrm{g} \cdot \mathrm{mL}^{-1}, 10 \mu \mathrm{g} \cdot \mathrm{mL}^{-1}\right.$ and $\left.5 \mu \mathrm{g} \cdot \mathrm{mL}^{-1}\right)$. Error bars represent the standard deviation of triplicate measurements. 


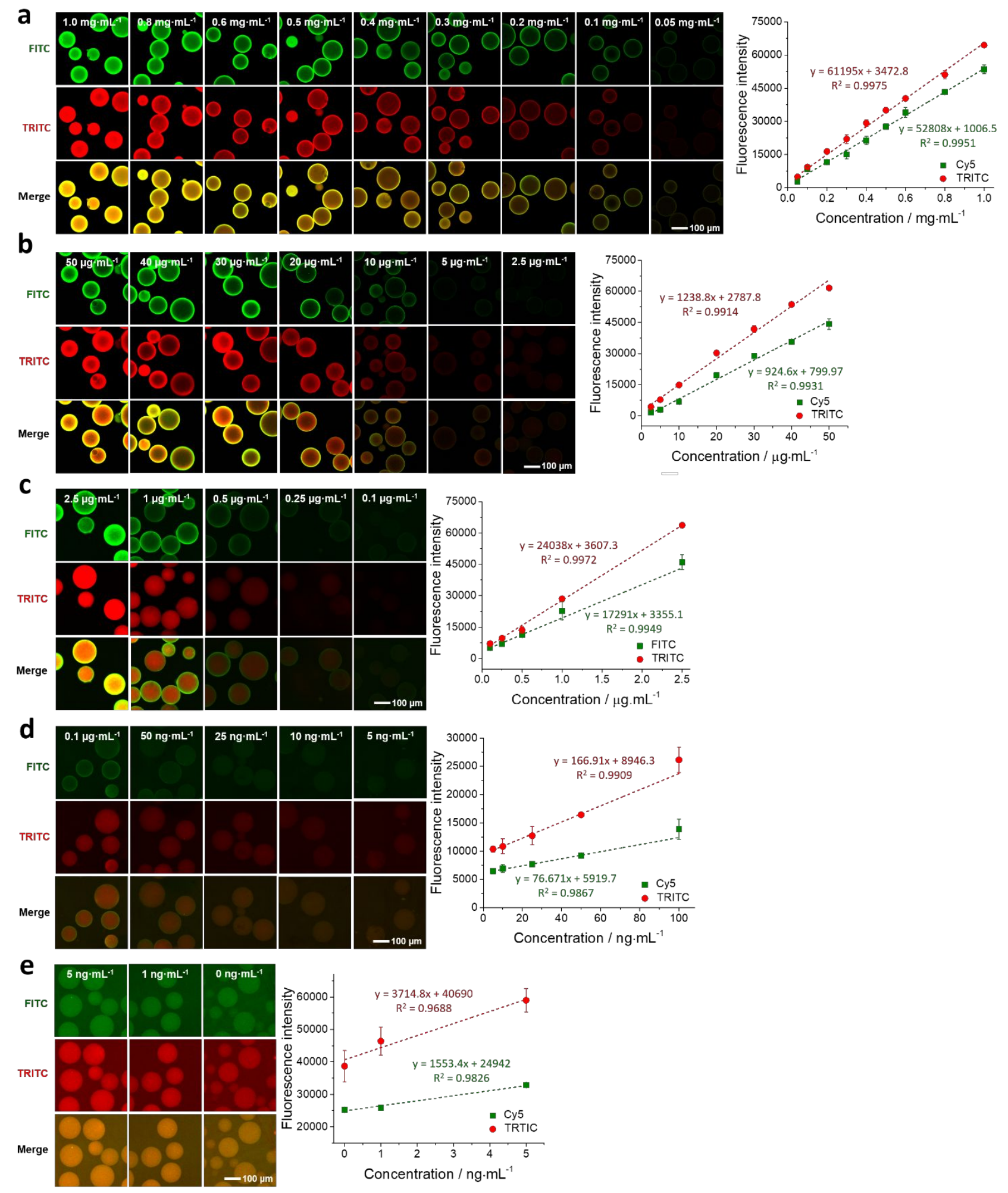

Figure S10. CLSM images and fluorescence intensity quantification of thiopropyl-Sepharose 6B beads coupled with different concentrations of anti-lgG-TRITC $\left(0 \mathrm{ng} \cdot \mathrm{mL}^{-1}\right.$ to $\left.1.0 \mathrm{mg} \cdot \mathrm{mL}^{-1}\right)$ and antigen IgG-Cy5 (0 $\mathrm{ng} \cdot \mathrm{mL}^{-1}$ to $\left.1.0 \mathrm{mg} \cdot \mathrm{mL}^{-1}\right)$. a) $0.05 \mathrm{mg} \cdot \mathrm{mL}^{-1}$ to $1.0 \mathrm{mg} \cdot \mathrm{mL}^{-1}$. b) 2.5 $\mu \mathrm{g} \cdot \mathrm{mL}^{-1}$ to $50 \mu \mathrm{g} \cdot \mathrm{mL}^{-1}$. c) $0.1 \mu \mathrm{g} \cdot \mathrm{mL}^{-1}$ to $2.5 \mu \mathrm{g} \cdot \mathrm{mL}^{-1}$. d) $5 \mathrm{ng} \cdot \mathrm{mL}^{-1}$ to $0.1 \mu \mathrm{g} \cdot \mathrm{mL}^{-1}$. e) $0 \mathrm{ng} \cdot \mathrm{mL}^{-1}$ to $5 \mathrm{ng} \cdot \mathrm{mL}^{-1}$ (16 scans sum). Error bars represent the standard deviation of triplicate measurements. Scale bar, $100 \mu \mathrm{m}$. 


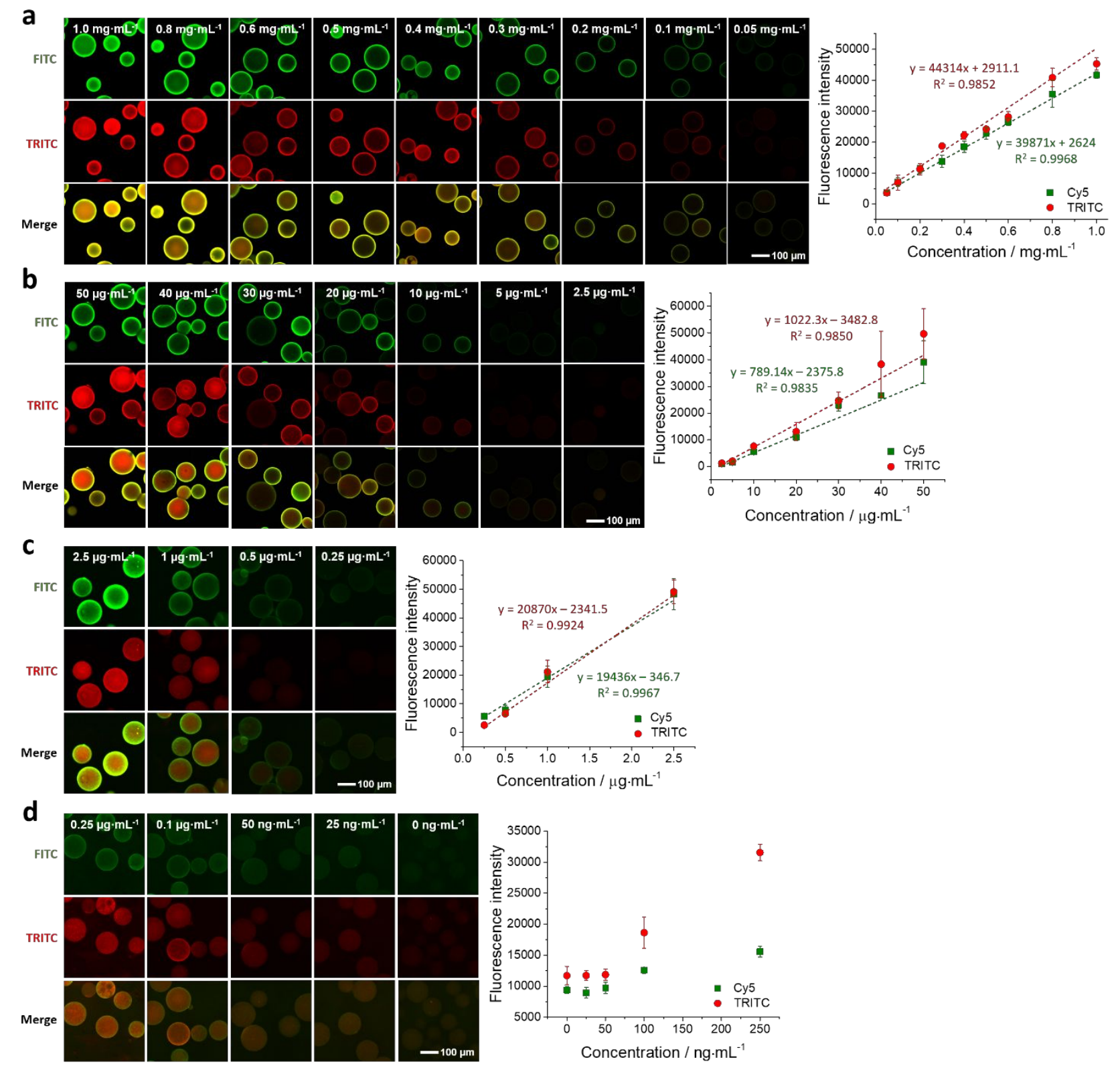

Figure S11. CLSM images and fluorescence intensity quantification of thiopropyl-Sepharose 6B beads with different concentrations of anti-IgG-TRITC $\left(0 \mathrm{ng} \cdot \mathrm{mL}^{-1}\right.$ to $\left.1.0 \mathrm{mg} \cdot \mathrm{mL}^{-1}\right)$ and IgGCy5 $\left(0 \mathrm{ng} \cdot \mathrm{mL}^{-1}\right.$ to $\left.1.0 \mathrm{mg} \cdot \mathrm{mL}^{-1}\right)$ with treatment of TCEP. a) $0.05 \mathrm{mg} \cdot \mathrm{mL}^{-1}$ to $1.0 \mathrm{mg} \cdot \mathrm{mL}^{-1} \cdot \mathrm{b}$ ) $2.5 \mu \mathrm{g} \cdot \mathrm{mL}^{-1}$ to $50 \mu \mathrm{g} \cdot \mathrm{mL}^{-1}$. c) $0.25 \mu \mathrm{g} \cdot \mathrm{mL}^{-1}$ to $2.5 \mu \mathrm{g} \cdot \mathrm{mL}^{-1}$. d) $0 \mathrm{ng} \cdot \mathrm{mL}^{-1}$ to $0.25 \mu \mathrm{g} \cdot \mathrm{mL}^{-1}$. Error bars represent the standard deviation of triplicate measurements. Scale bar, $100 \mu \mathrm{m}$. 
a
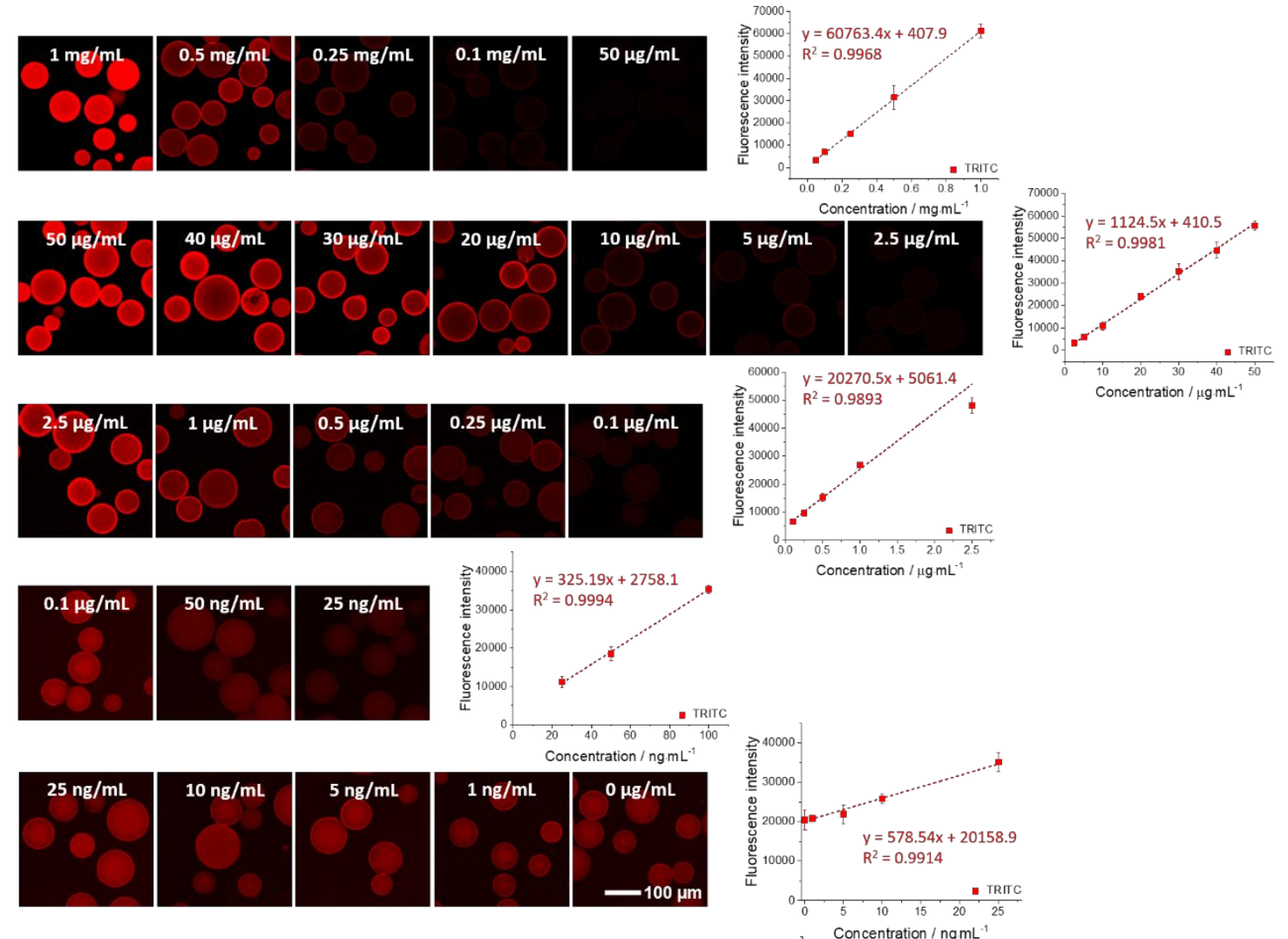

b
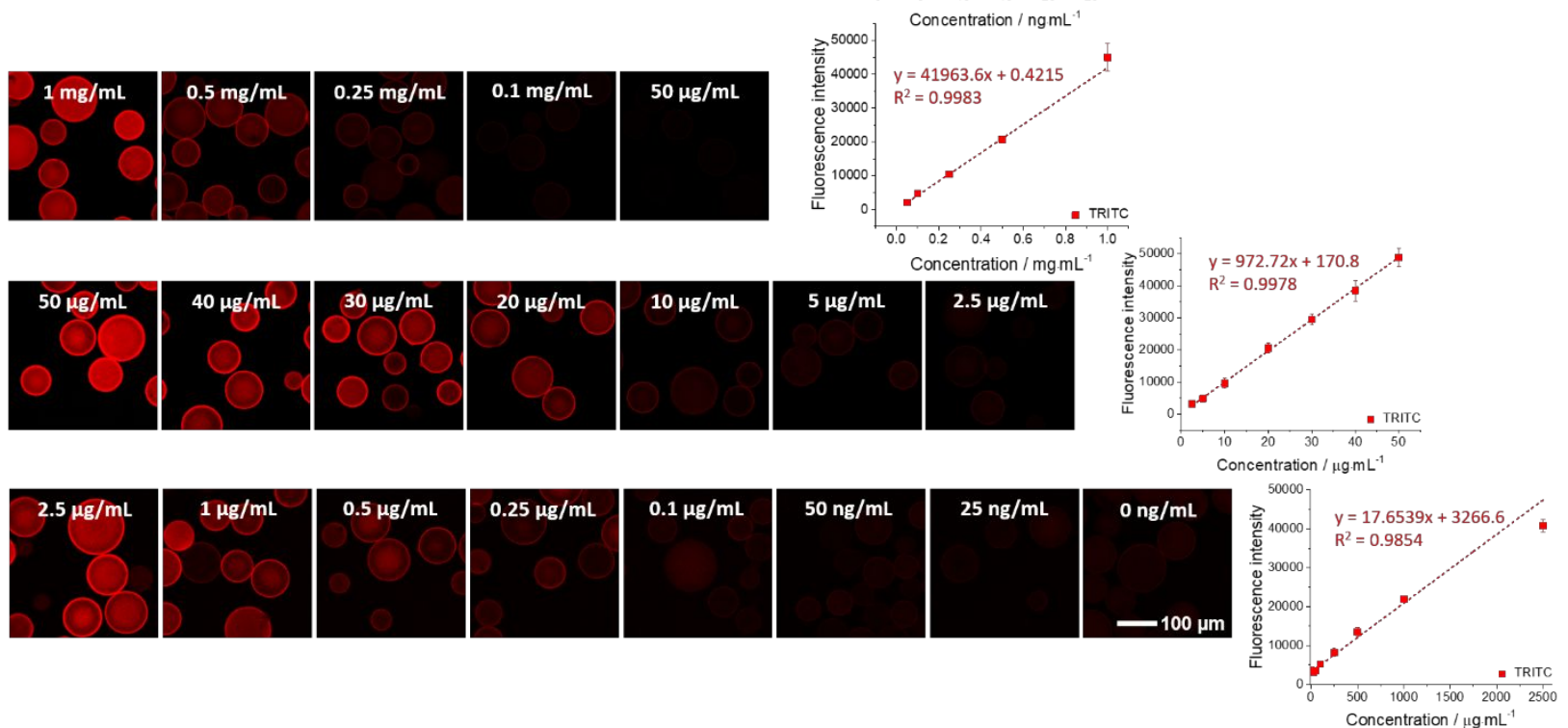

Figure S12. CLSM images and fluorescence intensity quantification of thiopropyl-Sepharose 6B beads linked with $0.5 \mathrm{mg} \cdot \mathrm{mL}^{-1}$ anti-lgG-TRITC and gradient concentrations of $\lg \mathrm{G}(0$ $\mathrm{ng} \cdot \mathrm{mL}^{-1}$ to $1.0 \mathrm{mg} \cdot \mathrm{mL}^{-1}$ ) before/after TCEP cleavage. a) Before TCEP treatment. b) After TCEP treatment. The parameters of confocal laser scanning microscopy (e.g. laser power, gain value, etc.) were adjusted to achieve the best fluorescence signals for each testing group. Error bars represent the standard deviation of triplicate measurements. Scale bar, $100 \mu \mathrm{m}$. 

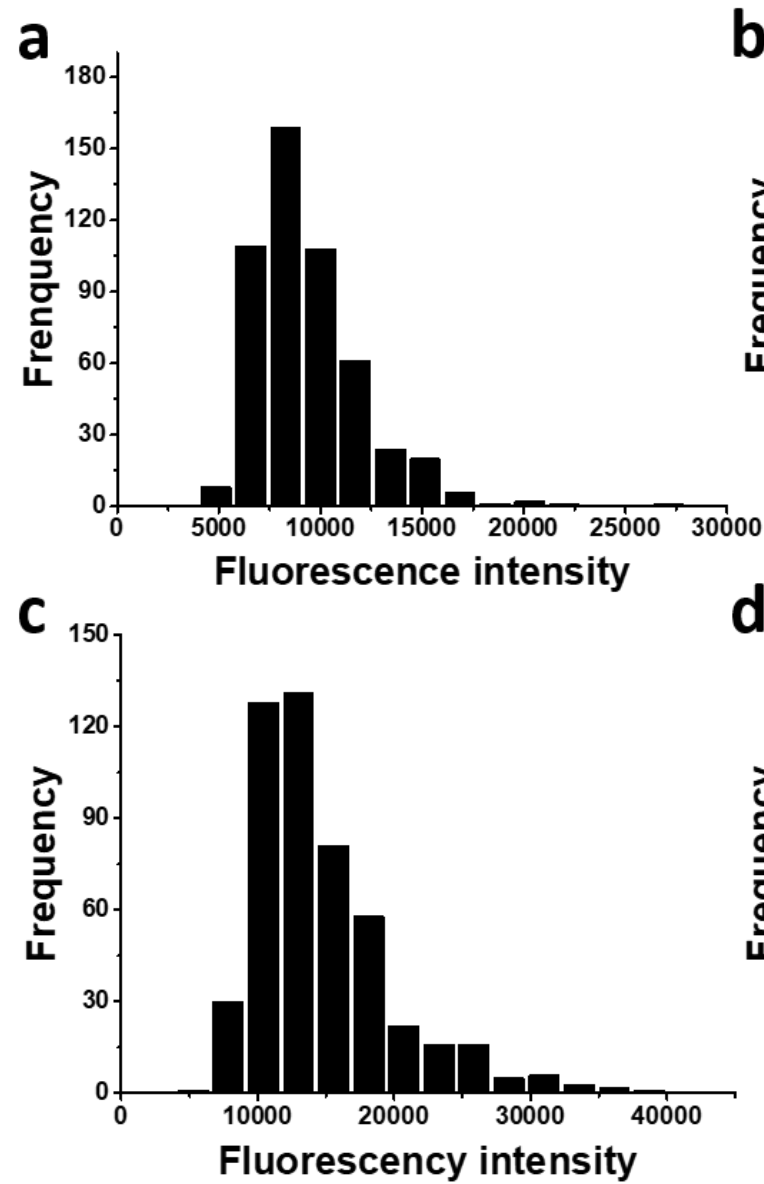

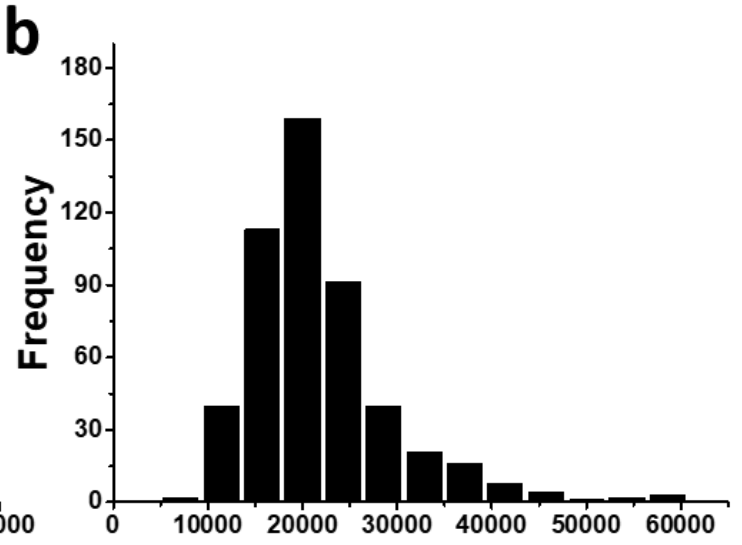

Fluorescence intensity

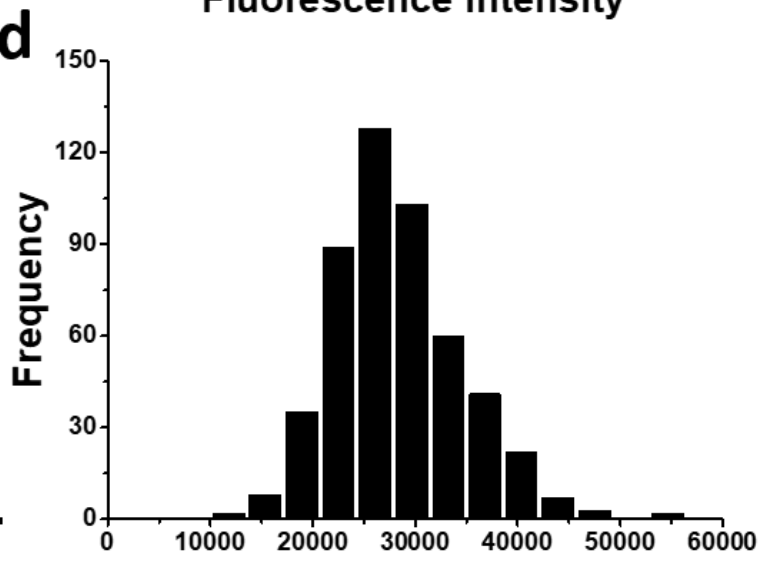

Fluorescence intensity

Figure S13. Fluorescence intensity distribution of thiopropyl-Sepharose $6 \mathrm{~B}$ bead coupled with capture antibody anti-human IgG-TIRTC and antigen human IgG-Cy5 (1:1 eq.). a) $0.1 \mathrm{mg} \cdot \mathrm{mL}^{-1}$. b) $50 \mu \mathrm{g} \cdot \mathrm{mL}^{-1}$. c) $10 \mu \mathrm{g} \cdot \mathrm{mL}^{-1}$. d) $1 \mu \mathrm{g} \cdot \mathrm{mL}^{-1}$. The parameters of confocal laser scanning microscopy (e.g. laser power, gain value, etc.) were adjusted to achieve the best fluorescence signals for each testing group. 


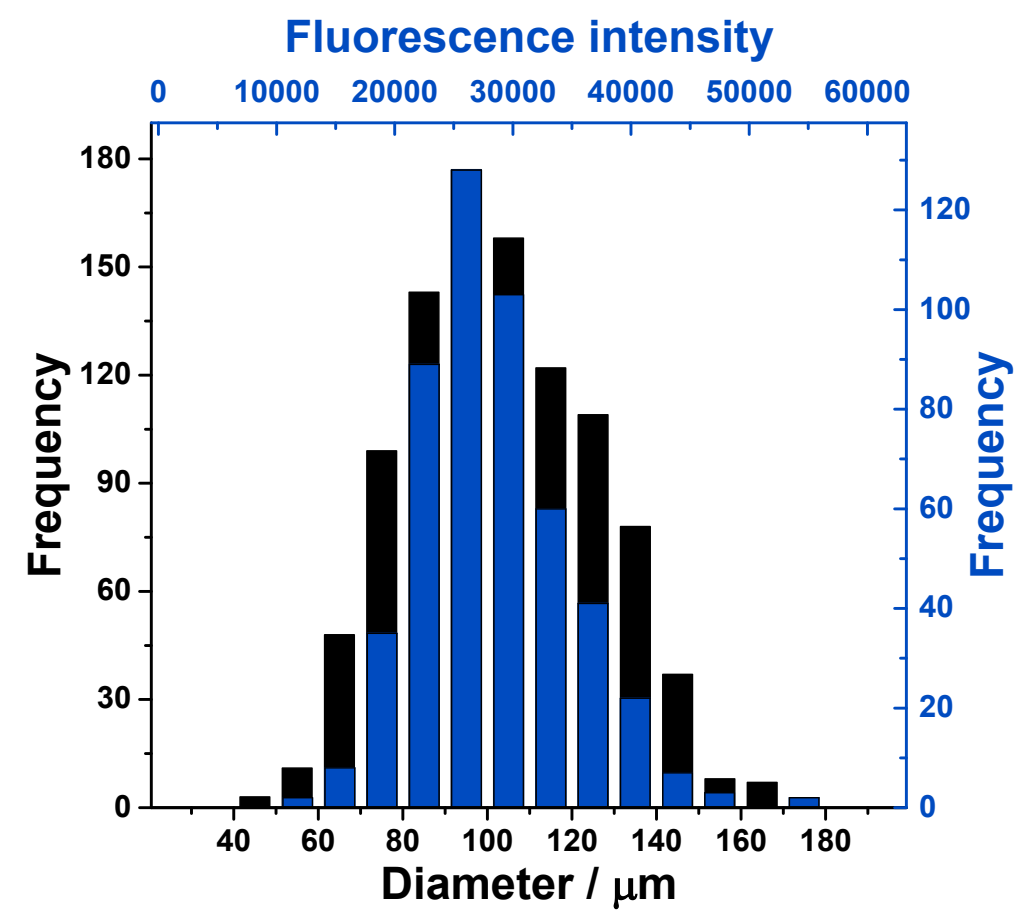

Figure S14. Thiopropyl-Sepharose 6B beads size distribution (1000 beads) and fluorescence intensity distribution of beads-immunocomplexes (anti-IgG-TRITC \& IgG-Cy5, $1.0 \mu \mathrm{gg} \cdot \mathrm{mL}^{-1}$ ). 
a
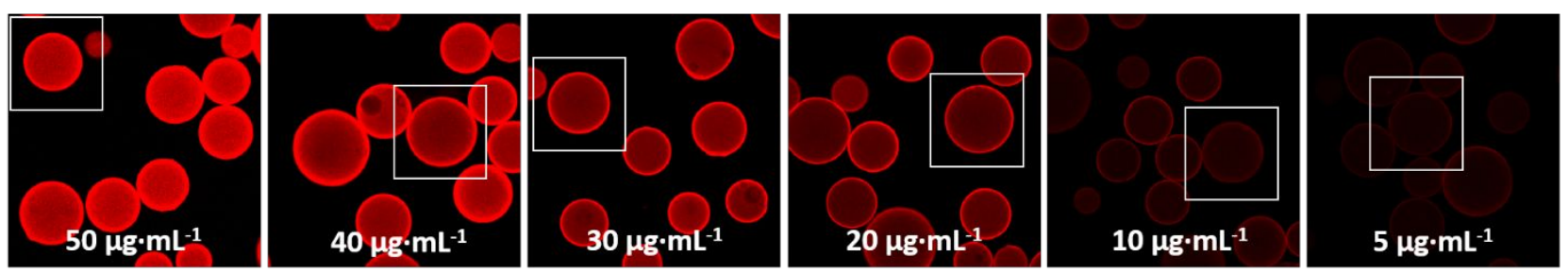

b
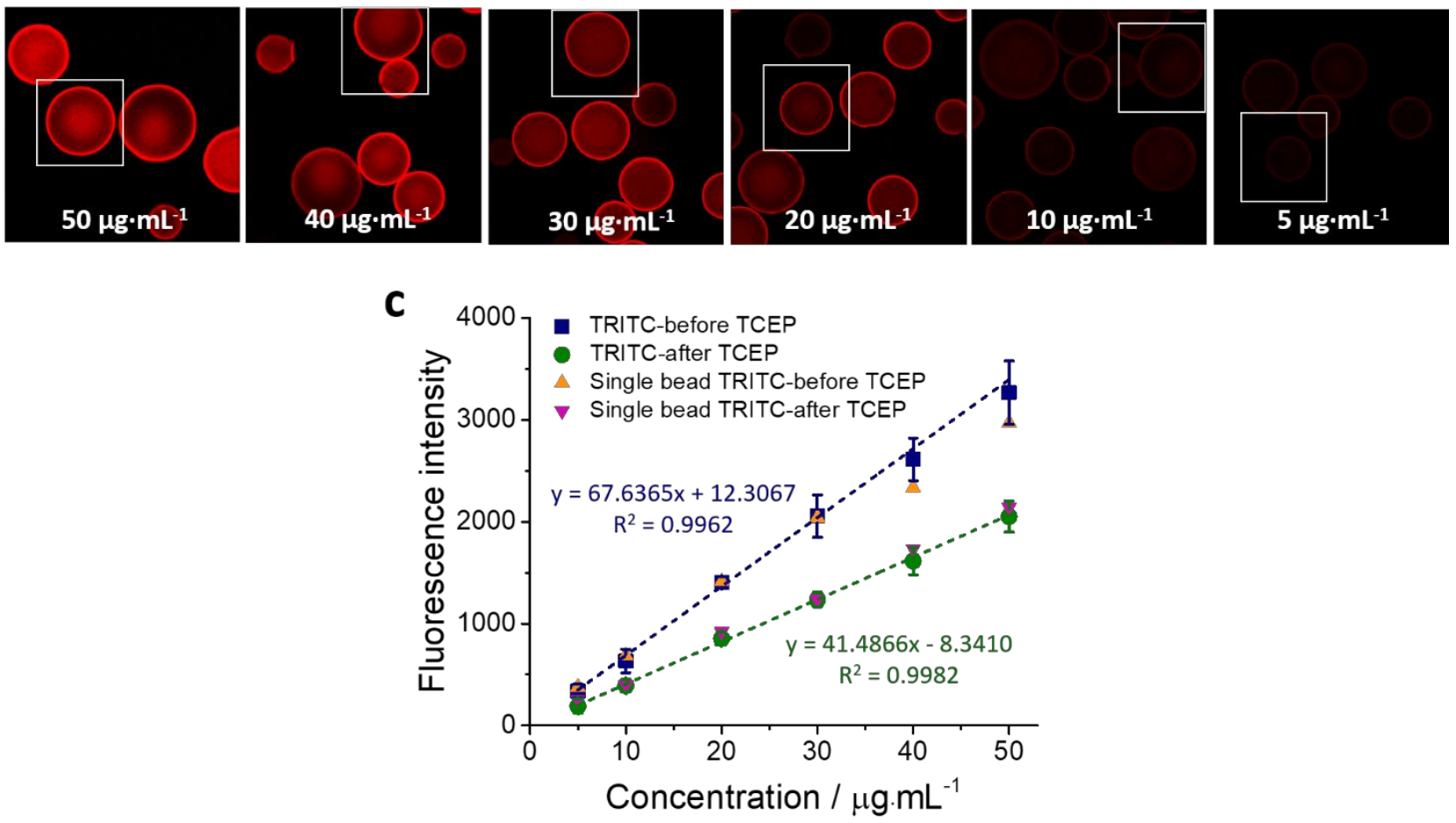

Figure S15. CLSM images and TRITC fluorescence intensity quantification $\left(5 \mu \mathrm{g} \cdot \mathrm{mL}^{-1}\right.$ to 50 $\mu \mathrm{g} \cdot \mathrm{mL}^{-1}$, single bead) of thiopropyl-Sepharose $6 \mathrm{~B}$ beads coupled with $0.5 \mathrm{mg} \cdot \mathrm{mL}^{-1}$ anti-lgGTRITC and gradient concentrations of IgG before/after TCEP cleavage. a) CLSM images before TCEP cleavage. b) CLSM images after TCEP cleavage. c) Single bead fluorescence intensity comparison with standard fluorescence intensity curve. Error bars represent the standard deviation of triplicate measurements. 
a

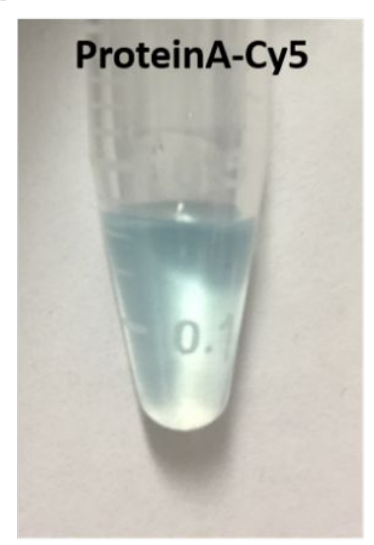

b

NTA 6B beads-

Protein A-Cy5

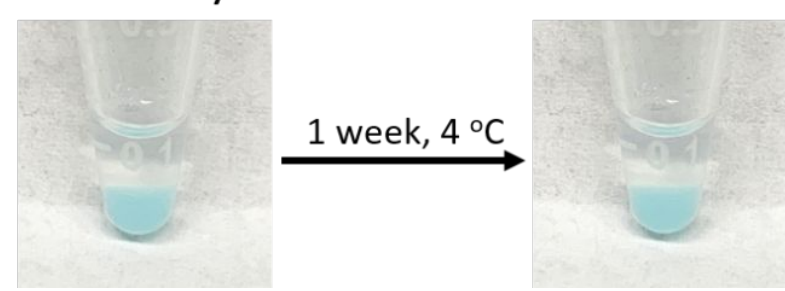

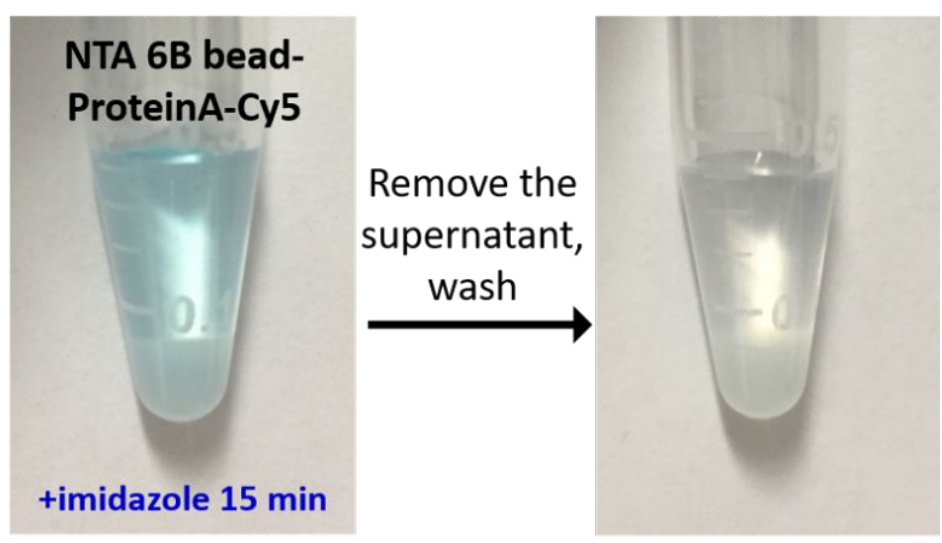

NTA 6B beads-

Protein A-Cy5

\& IgG-FITC

Figure S16. a) Studies of imidazole effect on Cy5 dye. b) Stability test of $\mathrm{Ni}^{2+}-\mathrm{NTA} 6 \mathrm{~B}$ beads modified with Protein A-Cy5 and IgG-FITC (1-week storage at $4{ }^{\circ} \mathrm{C}$ ). 


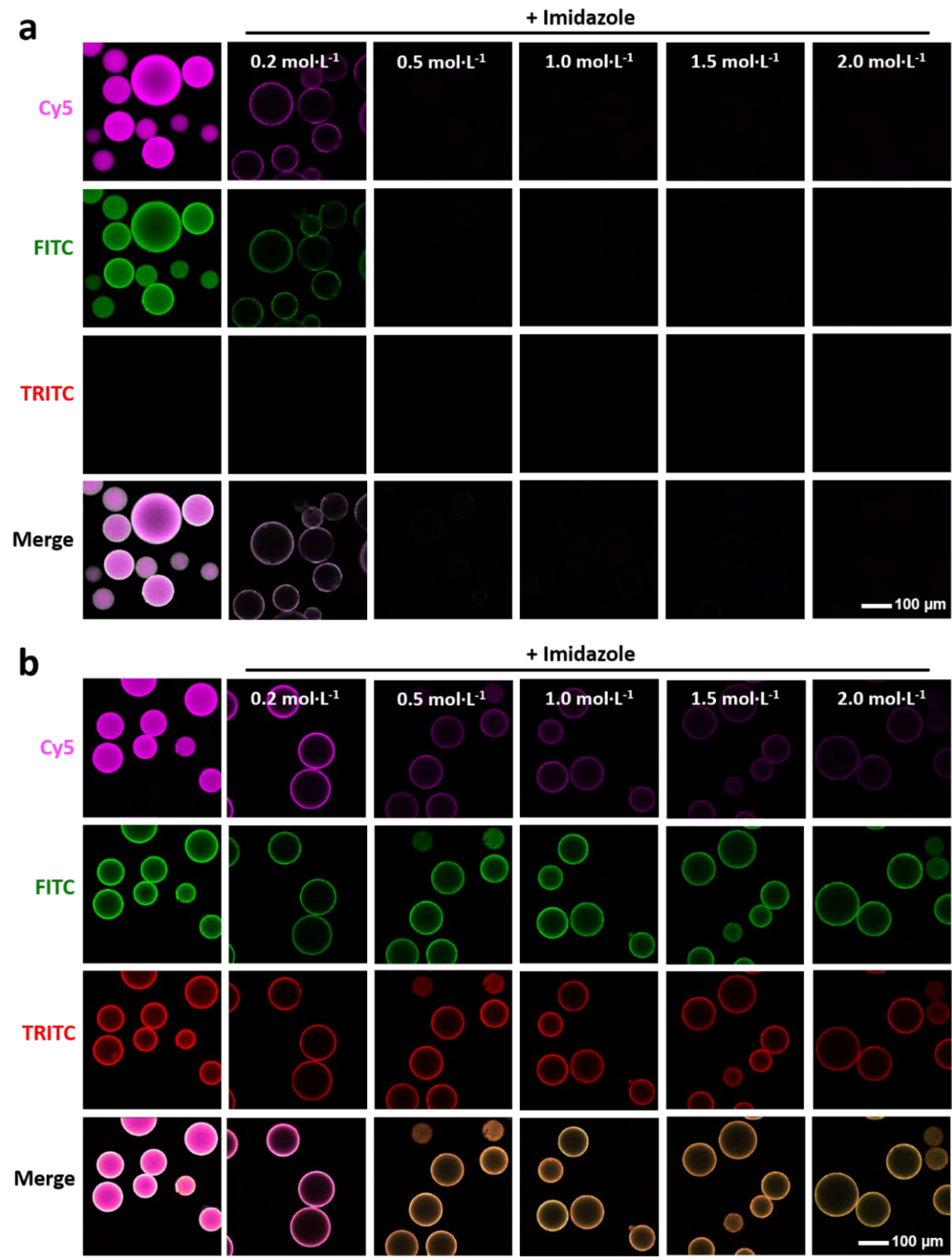

Figure S17. a) CLSM images of $\mathrm{Ni}^{2+}-\mathrm{NTA} 6 \mathrm{~B}$ beads modified with Protein A-Cy5 and antihuman IgG-FITC treated with different concentrations of imidazole. b) CLSM images of $\mathrm{Ni}^{2+}$ NTA 6B modified with Protein A-Cy5, anti-human IgG-FITC and human IgG-TRITC treated with different concentrations of imidazole solution (0.2 M, 0.5 M, 1.0 M, 1.5 M and 2.0 M). Scale bar, $100 \mu \mathrm{m}$. 
NTA 6B beads + proteinA-Cy5 \& anti-human IgG-TRITC \& human IgG-FITC
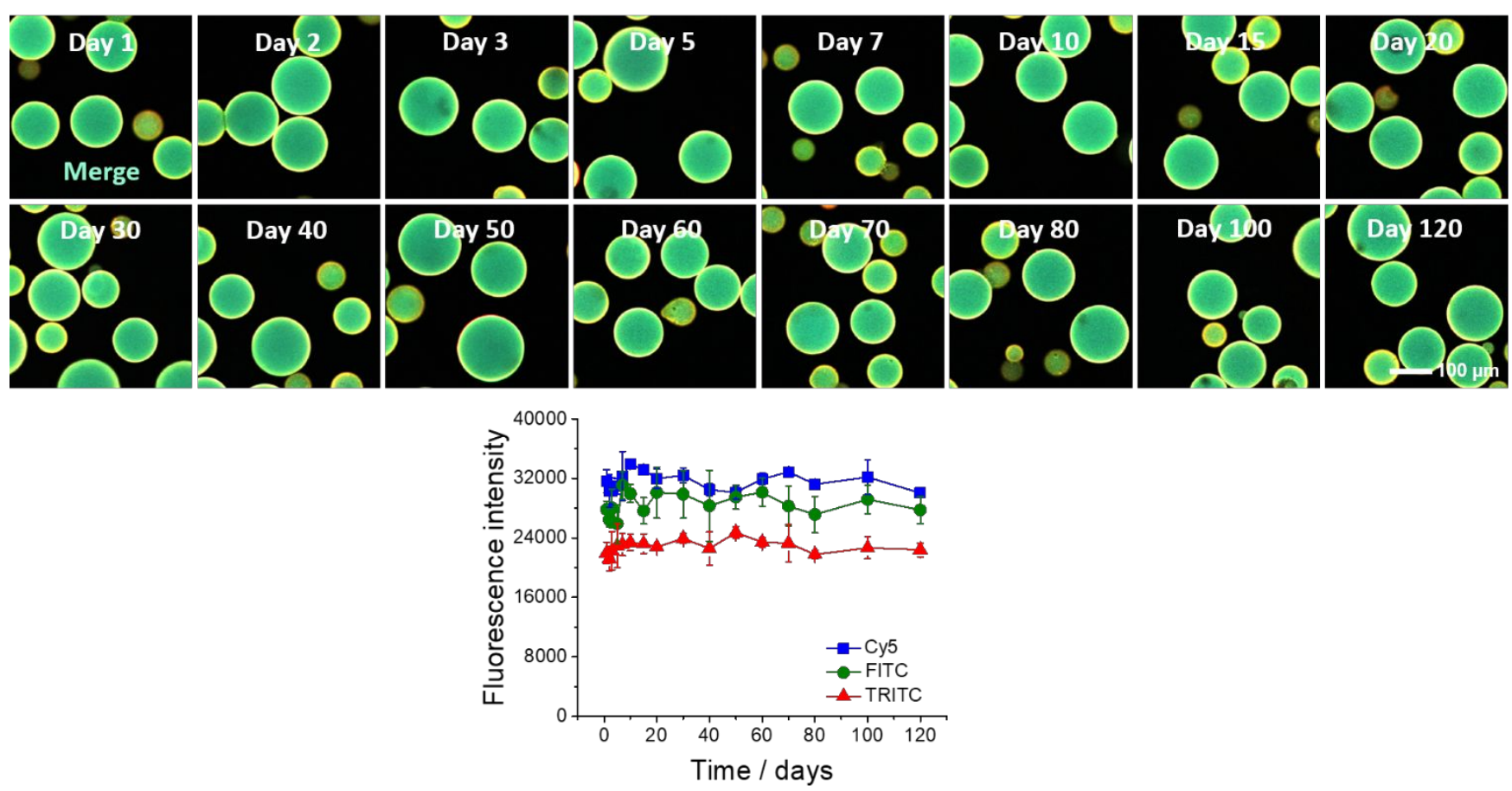

Figure S18. Stability test of $\mathrm{Ni}^{2+}-\mathrm{NTA} 6 \mathrm{~B}$ beads coupled with proteinA-Cy5, capture antibody anti-human IgG-FITC and antigen human IgG-TRITC (0-120 days). Merge: Cy5 channel-cyan, FITC channel-green, TRITC channel-red. Error bars represent the standard deviation of triplicate measurements. Scale bar, $100 \mu \mathrm{m}$. 


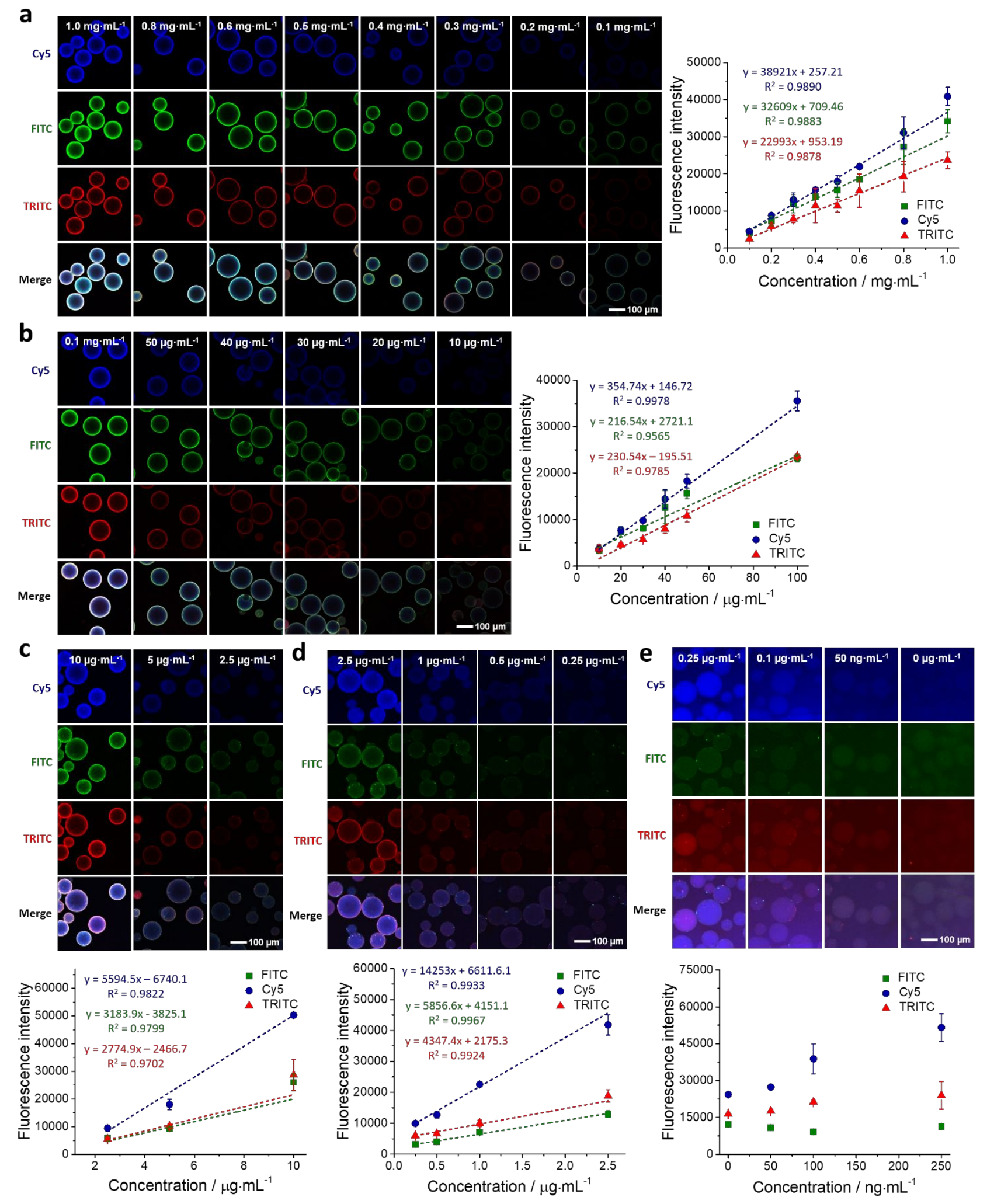

Figure S19. CLSM images and fluorescence intensity quantification of $\mathrm{Ni}^{2+}-\mathrm{NTA}$ 6B beads with different concentrations of Protein A-Cy5, anti-lgG-FITC and IgG-TRITC (0 ng. $\mathrm{mL}^{-1}$ to 1.0 $\mathrm{mg} \cdot \mathrm{mL}^{-1}$ ). a) $0.1 \mathrm{mg} \cdot \mathrm{mL}^{-1}$ to $1.0 \mathrm{mg} \cdot \mathrm{mL}^{-1} \cdot$ b) $10 \mu \mathrm{g} \cdot \mathrm{mL}^{-1}$ to $0.1 \mathrm{mg} \cdot \mathrm{mL}^{-1}$. c) $2.5 \mu \mathrm{g} \cdot \mathrm{mL}^{-1}$ to 10 $\mu \mathrm{g} \cdot \mathrm{mL}^{-1}$. d) $0.25 \mu \mathrm{g} \cdot \mathrm{mL}^{-1}$ to $2.5 \mu \mathrm{g} \cdot \mathrm{mL}^{-1}$. e) $0 \mathrm{ng} \cdot \mathrm{mL}^{-1}$ to $0.25 \mu \mathrm{g} \cdot \mathrm{mL}^{-1}$ (16 scans sum). Error bars represent the standard deviation of triplicate measurements. Scale bar, $100 \mu \mathrm{m}$. 


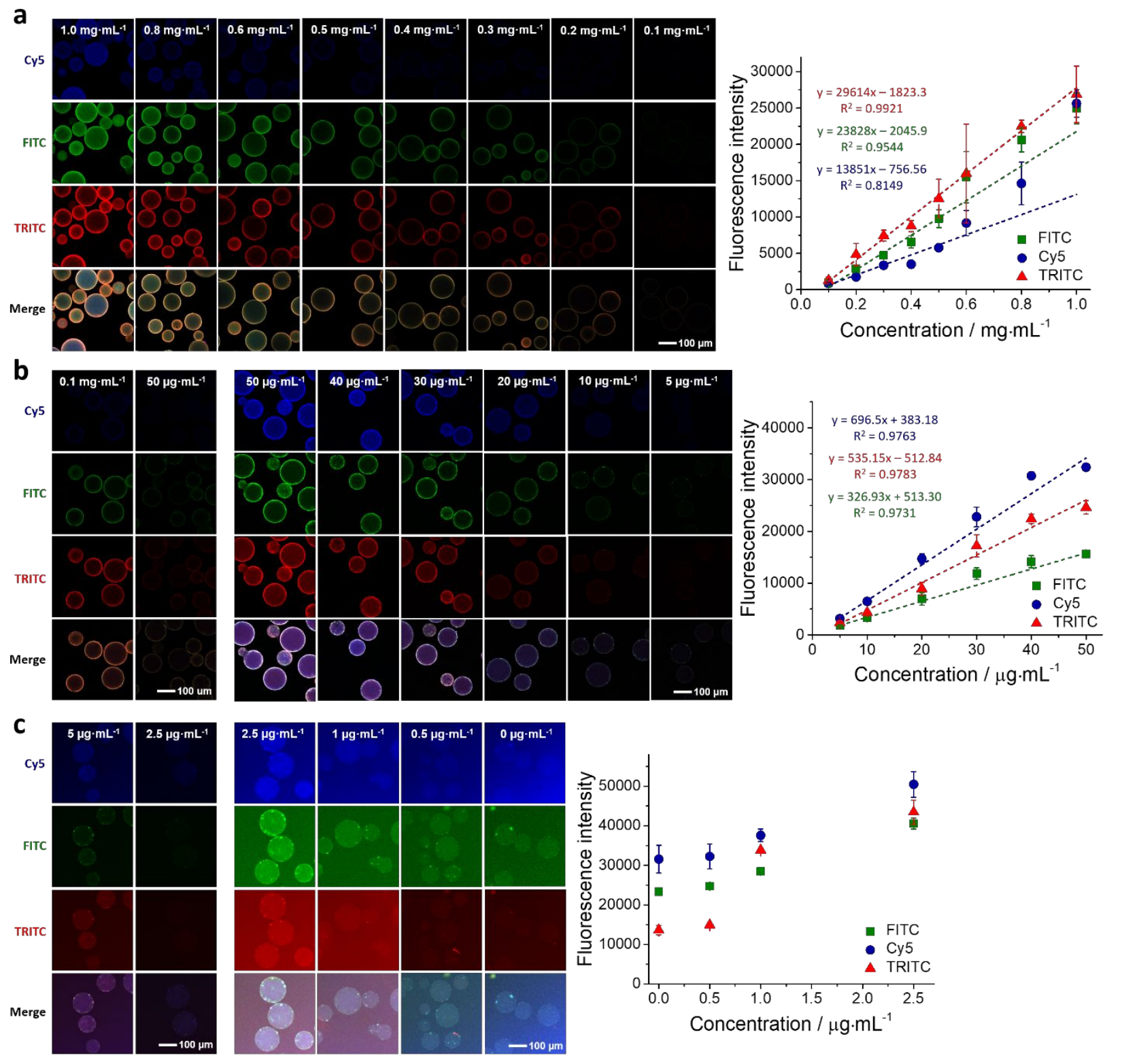

Figure S20. CLSM images and fluorescence intensity quantification of $\mathrm{Ni}^{2+}-\mathrm{NTA}$ 6B beads with different concentrations of Protein A-Cy5, anti-IgG-FITC and IgG-TRITC $\left(0 \mathrm{ng} \cdot \mathrm{mL}^{-1}\right.$ to 1.0 $\mathrm{mg} \cdot \mathrm{mL}^{-1}$ ) after imidazole treatment. a) $0.1 \mathrm{mg} \cdot \mathrm{mL}^{-1}$ to $1.0 \mathrm{mg} \cdot \mathrm{mL}^{-1}$. b) $5 \mu \mathrm{g} \cdot \mathrm{mL}^{-1}$ to $0.1 \mathrm{mg} \cdot \mathrm{mL}$ 1. c) $0 \mu \mathrm{g} \cdot \mathrm{mL}^{-1}$ to $5 \mu \mathrm{g} \cdot \mathrm{mL}^{-1}$ (16 scans sum). Error bars represent the standard deviation of triplicate measurements. Scale bar, $100 \mu \mathrm{m}$. 


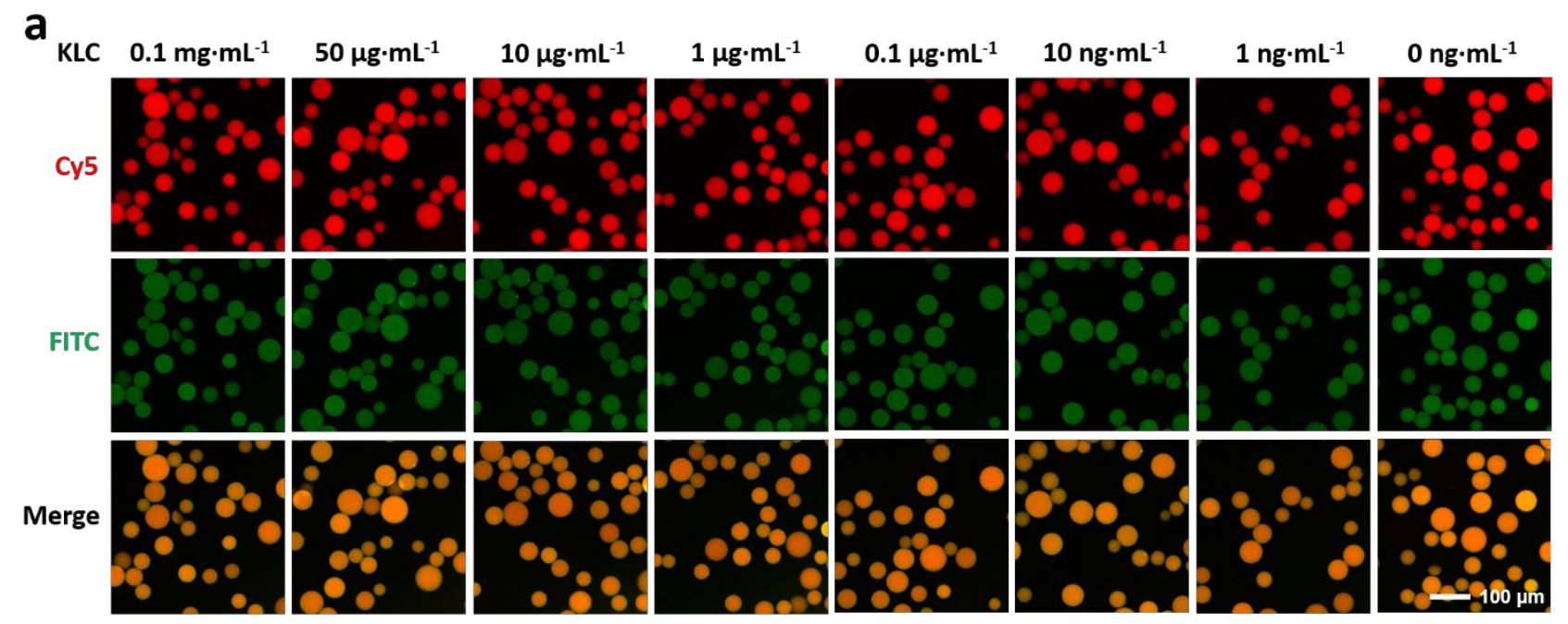

b
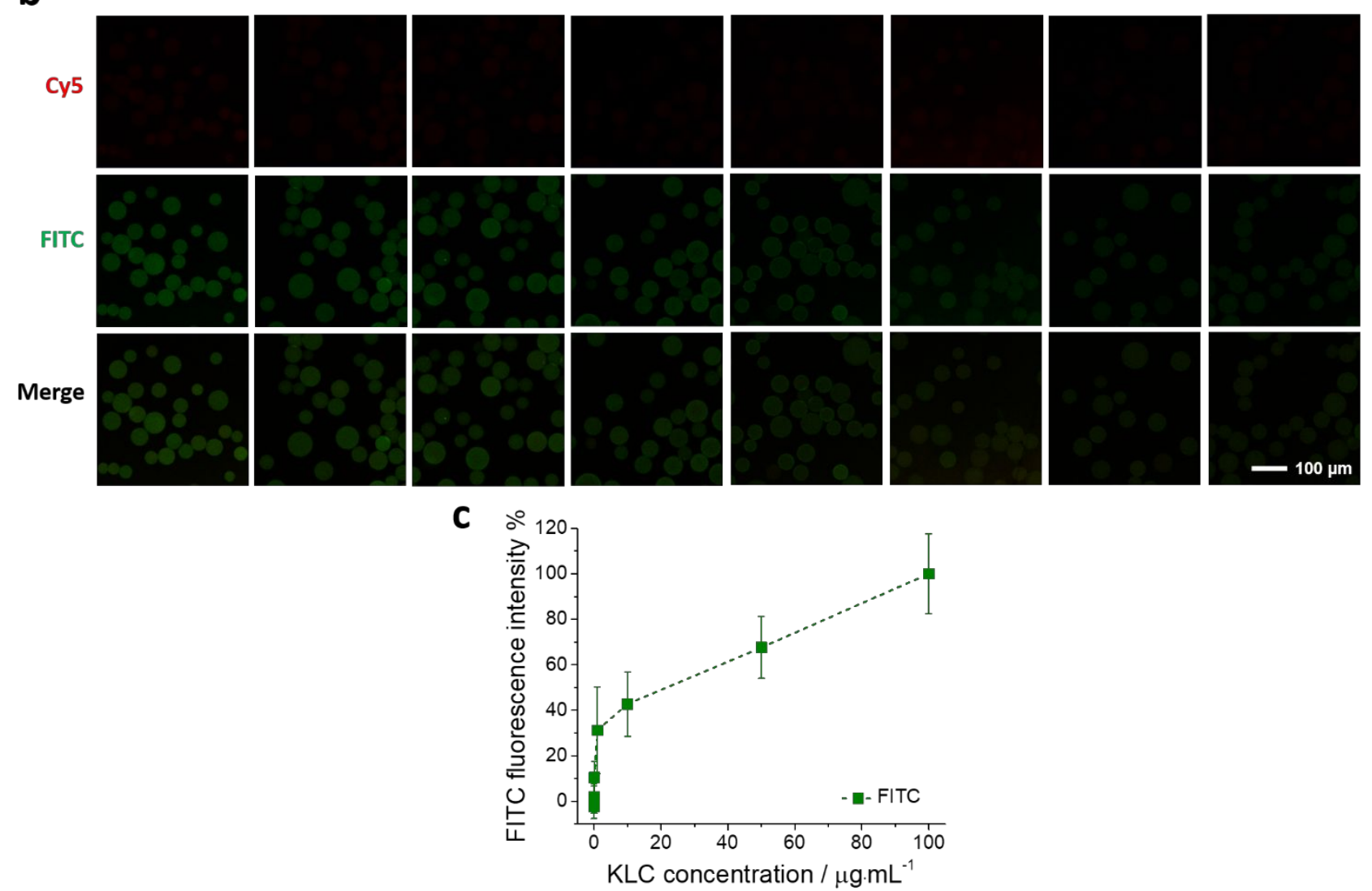

Figure S21. CLSM images and quantitative analysis of $\mathrm{Ni}^{2+}-\mathrm{NTA}$ Sephacryl S200 bead modified with (Protein A-Cy5 + anti-KLC IgG-FITC, ratio: 10:1) and different concentrations of $\mathrm{KLC}\left(0.1 \mathrm{mg} \cdot \mathrm{mL}^{-1}, 50 \mu \mathrm{g} \cdot \mathrm{mL}^{-1}, 10 \mu \mathrm{g} \cdot \mathrm{mL}^{-1}, 1 \mu \mathrm{g} \cdot \mathrm{mL}^{-1}, 0.1 \mu \mathrm{g} \cdot \mathrm{mL}^{-1}, 10 \mathrm{ng} \cdot \mathrm{mL}^{-1}, 1 \mathrm{ng} \cdot \mathrm{mL}^{-1}\right.$ and $0 \mathrm{ng} \cdot \mathrm{mL}^{-1}$ ). a) CLSM images before imidazole treatment. b) CLSM images after imidazole treatment. c) Quantitative analysis of FITC signal after imidazole treatment (background deleted). Error bars represent the standard deviation of triplicate measurements. Scale bar, $100 \mu \mathrm{m}$. 


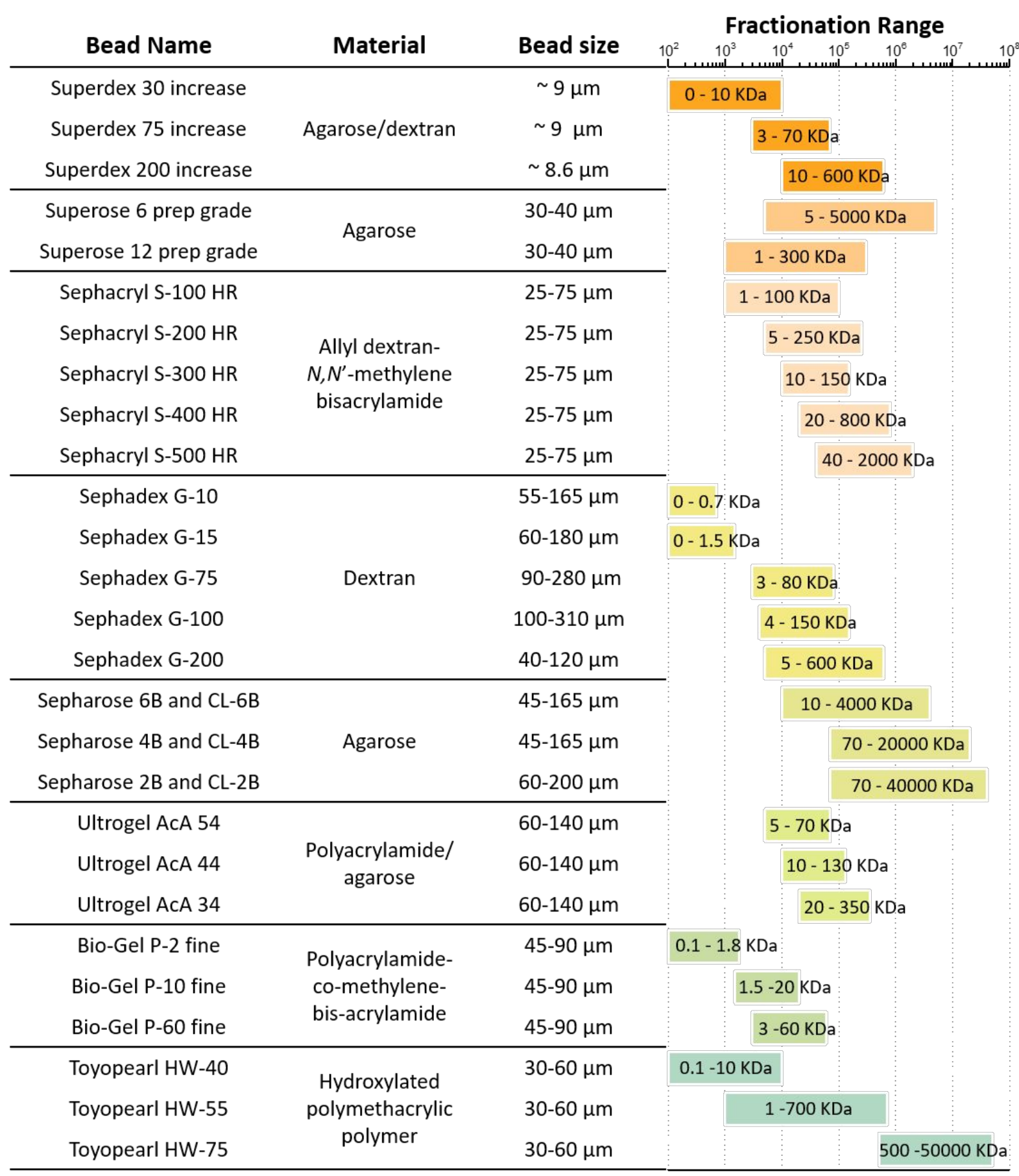

Figure S22. Gel-filtration media which has potential to be applied in ICEA and ELICEA platforms. This table lists several typical media used for gel-filtration and the information comes from the website of each product. Users should consult manufacturers' technical information regarding suitability for requirements. Note: Superdex, Superose, Sephacryl, Sephadex, Sepharose are registered trademarks of GE Healthcare. Ultrogel AcA is a registered trademark of Pall Corporation. Bio-Gel is a registered trademark of Bio-Rad Life Sciences. Toyopearl is a registered trademark of Tosoh Bioscience. 


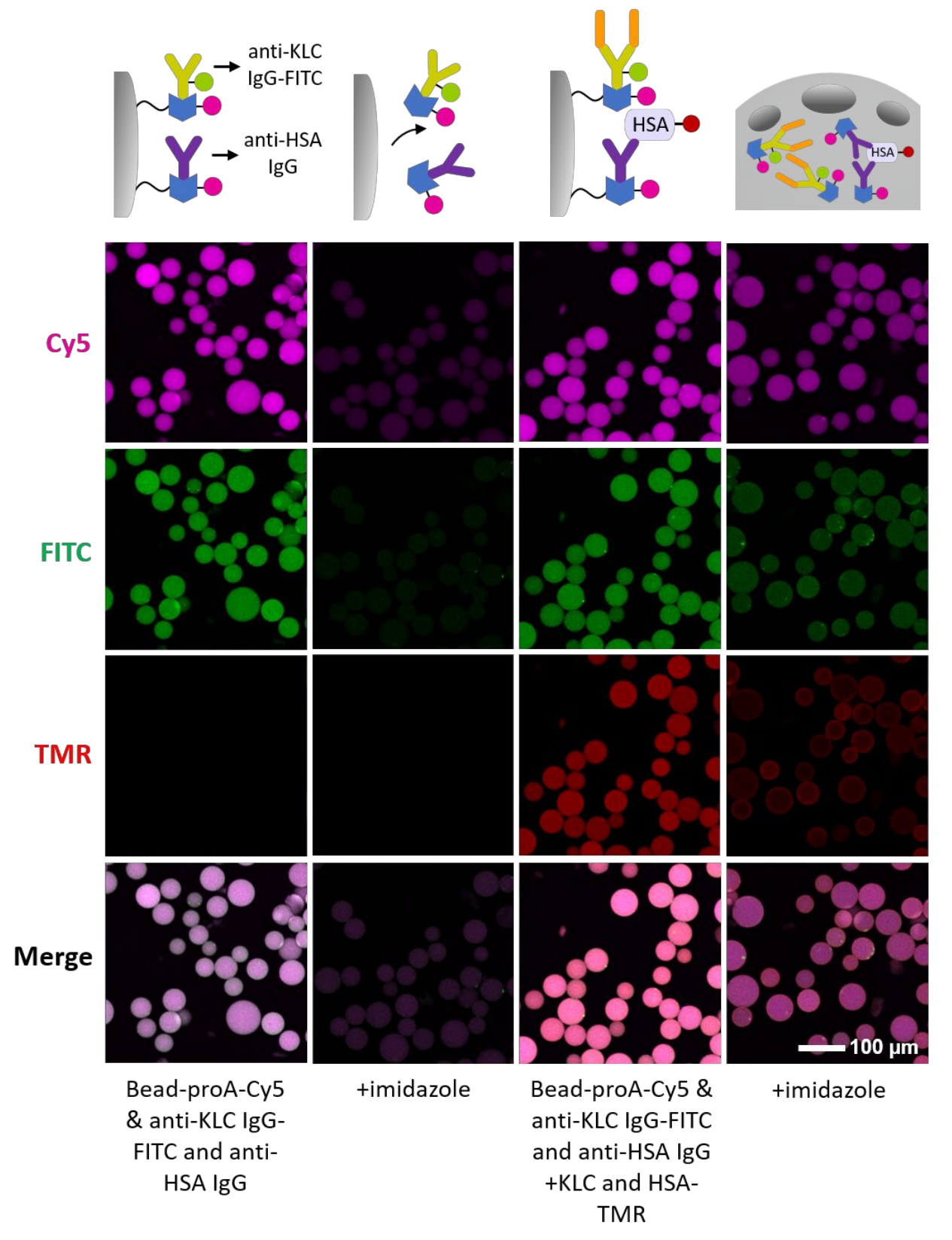

Figure S23. ICEA platform for multiplexed detection of target molecules in single $\mathrm{Ni}^{2+}-\mathrm{NTA}$ Sephacryl S200 beads. $\mathrm{Ni}^{2+}$-NTA Sephacryl S200 beads reacted with capture antibodies (antiKLC IgG-FITC and anti-HSA IgG) to detect target proteins (KLC and HSA-TMR in one sample) at the same time. Scale bar: $100 \mu \mathrm{m}$. 


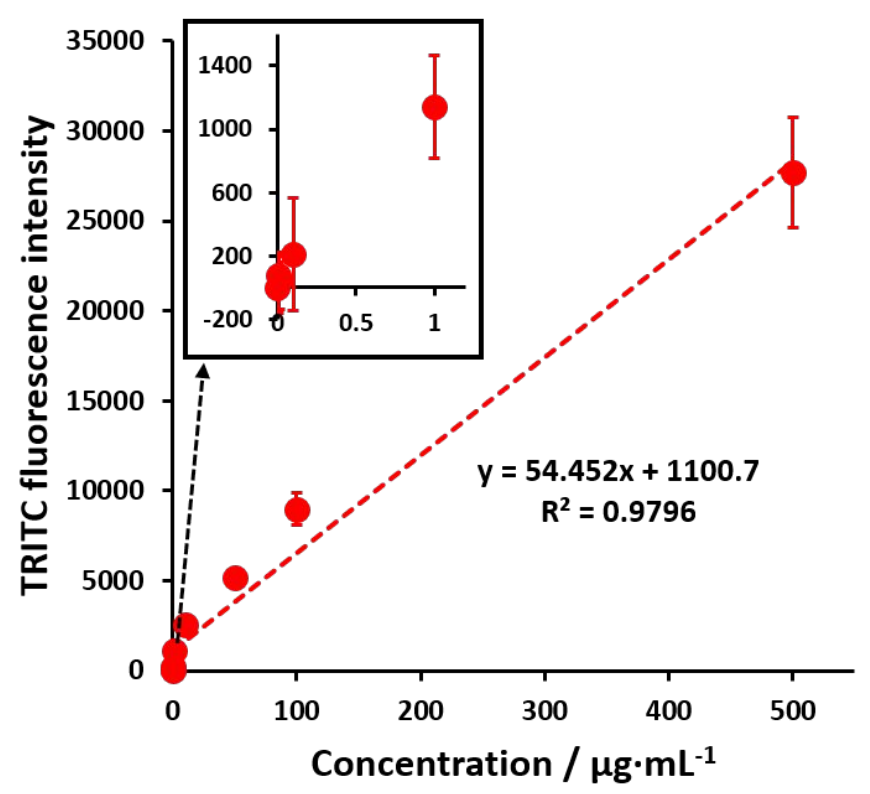

Figure S24. Urine test with anti-human IgG-TRITC modified thiopropyl-Sepharose 6B. Different concentrations of human IgG contained in different urine samples. Error bars represent the standard deviation of triplicate measurements. 


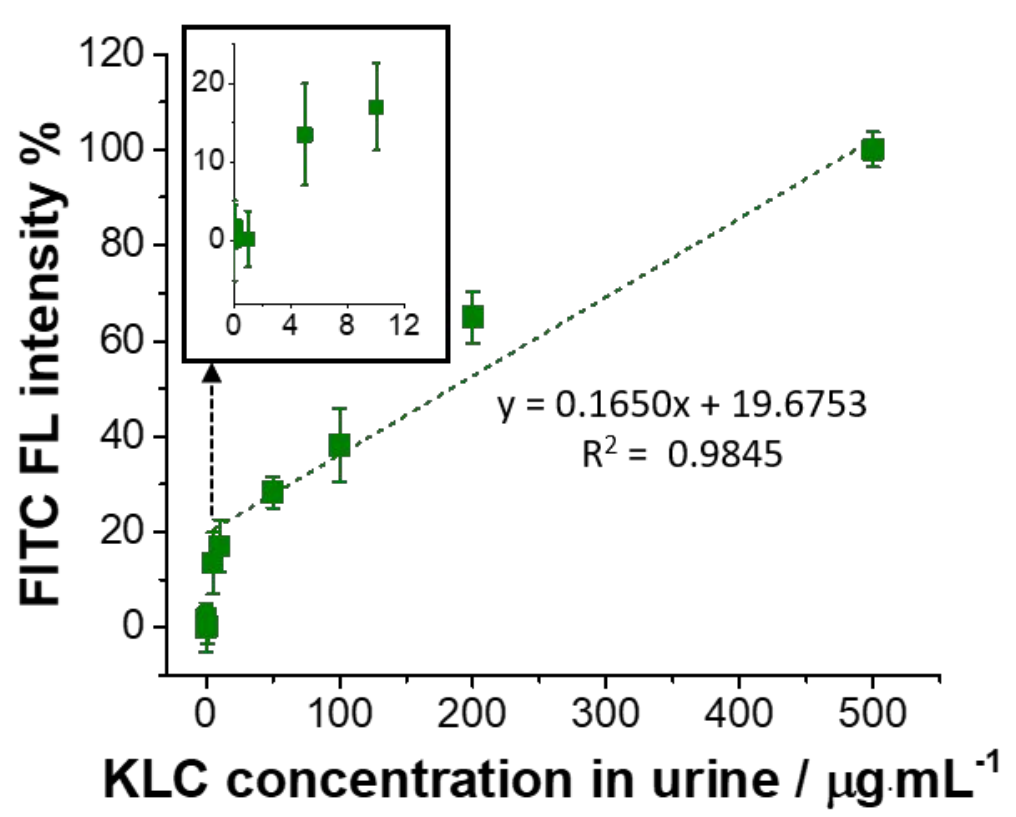

Figure S25. Urine test with anti-KLC-IgG-FITC modified Ni²+NTA Sephacryl S200 beads. Different concentrations of KLC (Bence-Jones Protein) contained in different urine samples. Error bars represent the standard deviation of triplicate measurements. 


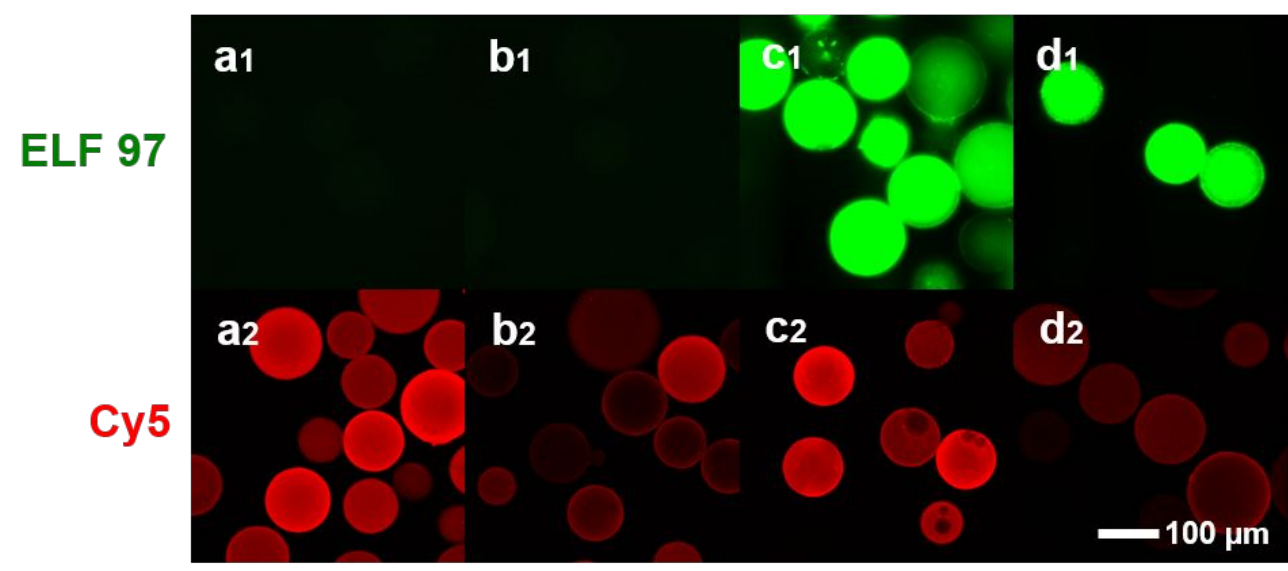

Figure S26. ELICEA platform consists of thiopropyl-Sepharose 6B beads, capture antibody anti-human IgG-alkaline phosphatase, target IgG-Cy5 and ELF 97 substrate. $a_{1}, a_{2}$ ) Beads with complex of anti-IgG-phosphatase and target IgG-Cy5. $b_{1}, b_{2}$ ) Beads with complex of antiIgG-phosphatase and target IgG-Cy5 after TCEP cleavage. $\mathrm{c}_{1}, \mathrm{C}_{2}$ ) Beads with complex with addition of ELF 97 substrate. $d_{1}, d_{2}$ ) Beads with complex after TCEP cleavage, then incubated with ELF 97 substrate. $\left(a_{1}, b_{1}, c_{1}, d_{1}\right.$ are fluorescence microscope images with excitation wavelength of $345 \mathrm{~nm}, a_{2}, b_{2}, c_{2}, d_{2}$ are CLSM images for Cy5 channel). Scale bar, $100 \mu \mathrm{m}$. 

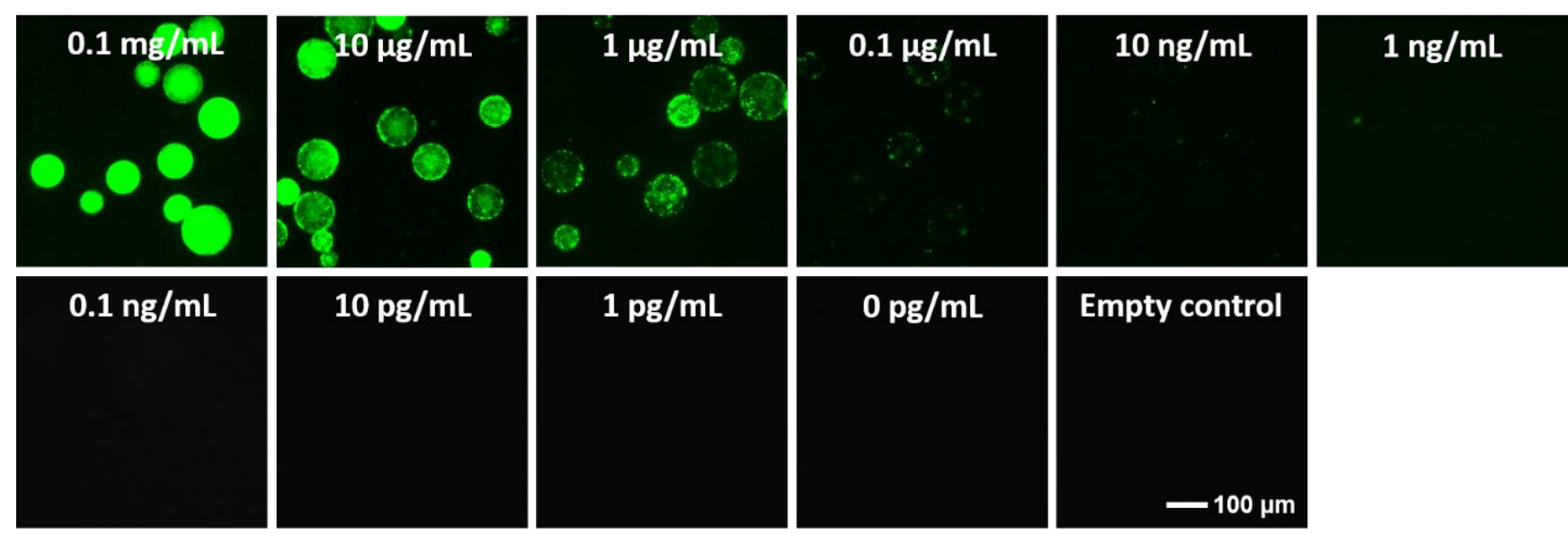

Empty control

Figure S27. Colorimetric detection of different concentrations of IgG-FITC with anti-lgGalkaline phosphatase modified thiopropyl-Sepharose 6B beads followed by addition of ELF 97 substrate. Scale bar, $100 \mu \mathrm{m}$. 


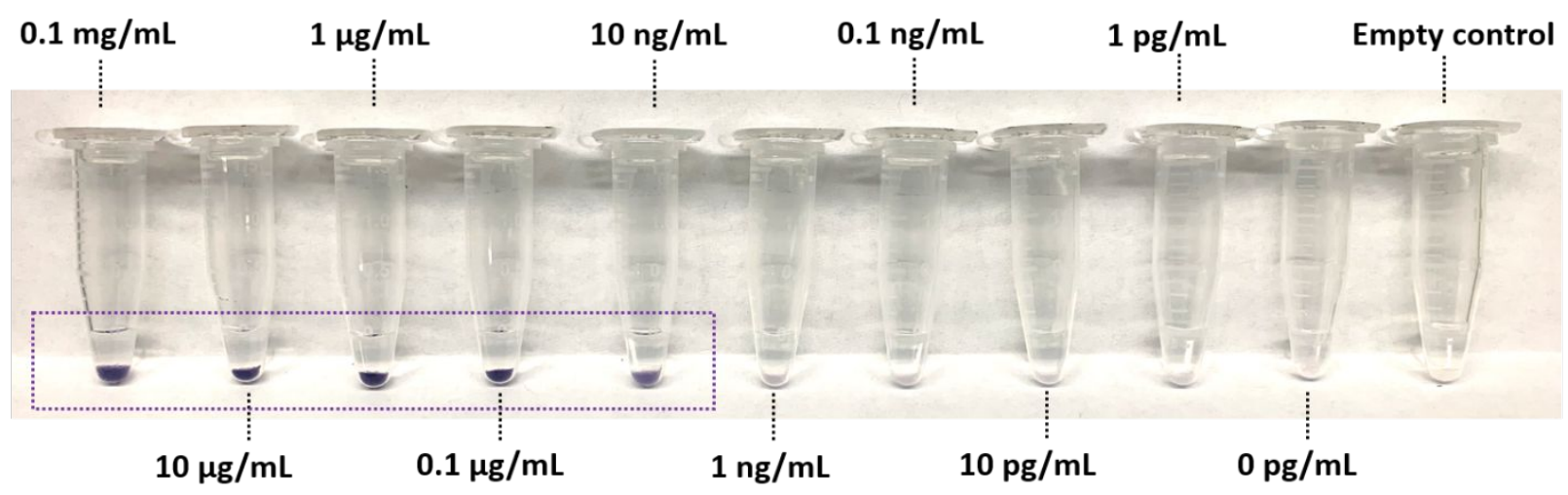

Figure S28. Colorimetric detection of different concentrations of IgG-FITC with anti-IgGalkaline phosphatase modified thiopropyl-Sepharose $6 \mathrm{~B}$ beads followed by addition of NBT/BCIP substrate. 
Thiopropyl beads

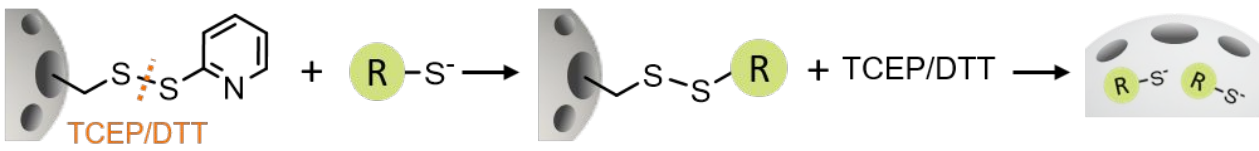

\section{$\mathrm{Ni}^{2+}-\mathrm{NTA}$ beads}

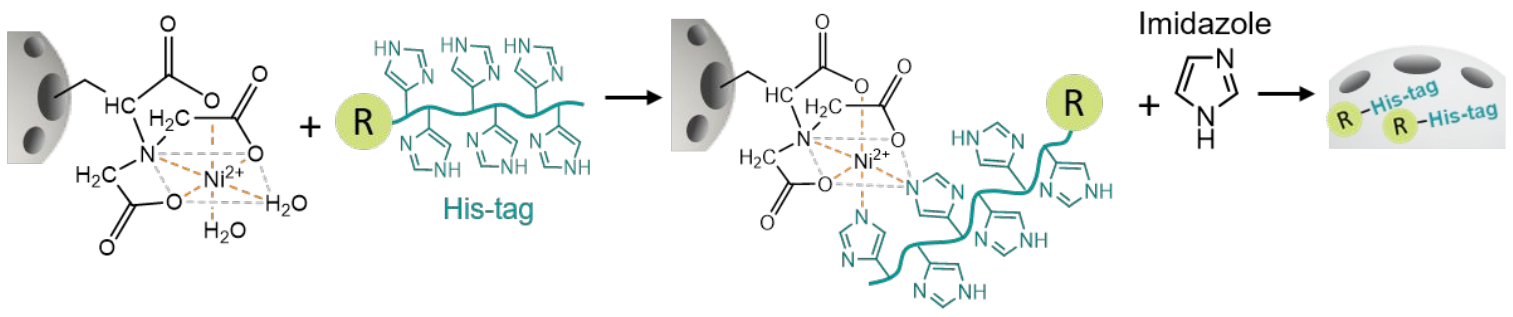

Glutathione beads

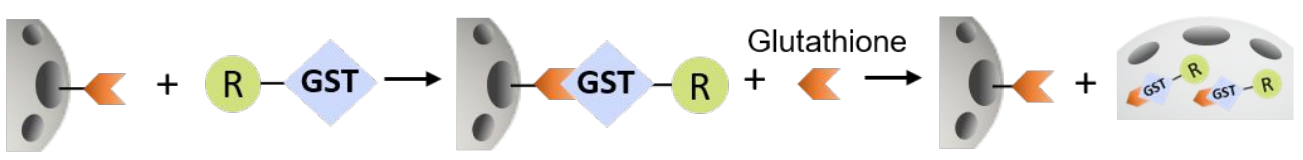

Iminobiotinylated beads

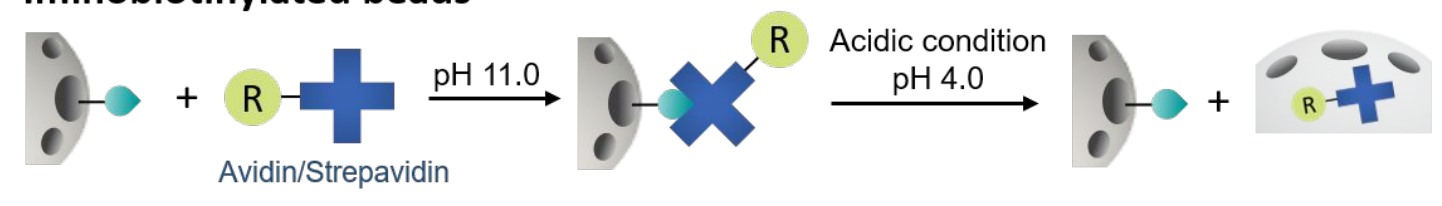

ssDNA/ssRNA beads
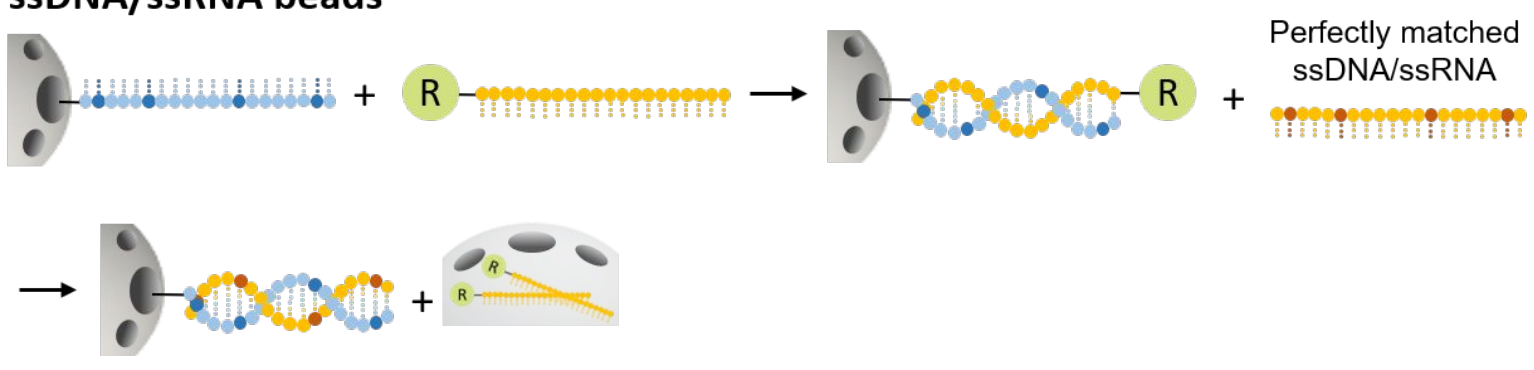

Figure S29. Alternative approaches to trigger/cleave immunocomplexes from gel filtration beads. 


\section{Author Contributions}

Y. Gong developed the research approach, performed all experiments, analyzed the data and wrote the manuscript. G. Marriott conceived the technology, designed and supervised the study, and wrote the manuscript. 